\title{
Oxygen Deprivation-induced Injury to Isolated Rabbit Kidney Tubules
}

\author{
Joel M. Weinberg \\ Departments of Internal Medicine, University of Michigan, and Veterans Administration Medical Center, Ann Arbor, Michigan 48109
}

\begin{abstract}
The utility of freshly isolated suspensions of rabbit tubules enriched in proximal segments for studying the pathogenesis of oxygen deprivation-induced renal tubular cell injury was evaluated. Oxygenated control preparations exhibited very good stability of critical cell injury-related metabolic parameters including oxygen consumption, cell cation homeostasis, and adenine nucleotide metabolism for periods in excess of $2 \mathrm{~h}$. Highly reproducible models of oxygen deprivation-induced injury and recovery were developed and alterations of injury-related metabolic parameters in these models were characterized in detail. When oxygen deprivation was produced under hypoxic conditions, tubules sustained widespread lethal cell injury and associated metabolic alterations within 15-30 min. However, when oxygen deprivation was produced under simulated ischemic conditions, tubules tolerated 30-60 min with only moderate amounts of lethal cell injury occurring, a situation similar to that seen with ischemia in vivo. Like ischemia in vivo, simulated ischemia in vitro was characterized by a fall in pH during oxygen deprivation. No such fall in pH occurred in the hypoxic model. To test whether this fall in pH could contribute to the protection seen during simulated ischemia in vitro, tubules were subjected to hypoxia at medium pHs ranging from 7.45 to 6.41. Striking protection from hypoxic injury was seen as $\mathrm{pH}$ was reduced with maximal protection occurring in tubules made hypoxic at pHs below 7.0. Measurements of injury-associated metabolic parameters suggested that the protective effect of reduced $\mathrm{pH}$ may be mediated by $\mathrm{pH}$ induced alterations of tubule cell $\mathrm{Ca}^{++}$metabolism. This study has, thus, defined and characterized in detail a new and extremely versatile model system for the study of oxygen deprivation-induced cell injury in the kidney and has established that $\mathrm{pH}$ alterations play a major role in modulating such injury.
\end{abstract}

\section{Introduction}

The pathogenesis of ischemic acute renal failure involves a complex interplay among injury to renal tubular epithelial cells, the

Some of the data in this study have been reported in abstract form (1984. Clin. Res. 32:1774; 1985. Kidney Int. 27:231) and were presented in November 1984 at the Midwest Section Meeting of the American Federation for Clinical Research, Chicago, IL, and in December 1984 to the American Society of Nephrology, Washington, DC. Dr. Weinberg is the recipient of Research Career Development Award AM 01337 from the National Institutes of Health.

Address reprint requests to Dr. Weinberg, D3249 MPB, Box 19, University of Michigan Medical Center, Ann Arbor, MI 48109.

Received for publication 26 November 1984 and in revised form 2 April 1985

J. Clin. Invest.

(C) The American Society for Clinical Investigation, Inc.

$0021-9738 / 85 / 09 / 1193 / 16 \$ 1.00$

Volume 76, September 1985, 1193-1208 effects of such injury on nephronal function and renal hemodynamics, and the effects of these factors on renal tubular cell viability and functional integrity $(1,2)$. Although patterns of injury differ somewhat between animal models and human ischemic acute renal failure $(3,4)$, tubular cell injury appears to be a common and necessary event for ischemic acute renal failure in each of these settings, and increasing interest has focused on its pathogenesis over the past several years. Furthermore, a variety of protective maneuvers with apparent efficacy to ameliorate renal tubular cell injury and the associated acute renal failure including treatment with osmotic agents, calcium channel blockers, and adenine nucleotides have been reported (5-7). However, the structural heterogeneity of the kidney and the reciprocal interactions between tubular cell injury and nephronal and hemodynamic processes occurring in vivo have limited information about pathogenetic mechanisms of tubular cell injury and protection from it that can be obtained from studies in vivo. Isolated tubule preparations studied both as individually perfused tubules and tubule suspensions have provided substantial insights into the normal physiology of the renal tubular epithelium (810). Freshly isolated intact cell preparations have been applied to the study of cell injury in a number of tissues including, to a limited extent, the kidney (11-16). The present study establishes freshly isolated suspensions of rabbit tubules enriched in proximal segments as a highly versatile system for studying the effects of oxygen deprivation on critical metabolic parameters involved in the pathogenesis of renal tubule cell injury, identifies major differences in the susceptibility of tubules to such injury as a function of whether oxygen deprivation is produced under hypoxic or under simulated ischemic conditions, and implicates $\mathrm{pH}$ as a major factor contributing to the differences between hypoxic and ischemic injury.

\section{Methods}

Animals. Female New Zealand White rabbits (Langshaw Farms, Augusta, MI) weighing an average of $2.5 \mathrm{~kg}$ were used for these studies.

Tubule isolation. Rabbits were anesthetized by injection of $25 \mathrm{mg} /$ $\mathrm{kg}$ sodium thiamylal into an ear vein. The abdominal cavity was opened, and both kidneys were rapidly removed and were immediately placed in an ice-cold solution containing $115 \mathrm{mM} \mathrm{NaCl}, 2.1 \mathrm{mM} \mathrm{KCl}, 25 \mathrm{mM}$ $\mathrm{NaHCO}_{3}, 2.4 \mathrm{mM} \mathrm{KH}_{2} \mathrm{PO}_{4}, 1.2 \mathrm{mM} \mathrm{CaCl}_{2}$, and $2.5 \mathrm{mM} \mathrm{MgSO}_{4}$ previously gassed with and kept under $95 \% \mathrm{O}_{2} / 5 \% \mathrm{CO}_{2}$ (solution $\mathrm{A}$ ). The rabbit was then killed with an overdose of thiamylal. The renal cortices were dissected on an ice-cold tile and were minced into small slices with a razor blade. The entire cortex from one rabbit was then placed into $24 \mathrm{ml}$ of a solution with an electrolyte concentration identical to solution A except for a $\mathrm{CaCl}_{2}$ concentration of $2.5 \mathrm{mM}$, a phosphate concentration of $1.2 \mathrm{mM}$, and the addition of $25 \mathrm{mM}$ mannitol, $2.5 \mathrm{mg} / \mathrm{ml}$ fatty acidfree bovine serum albumin (Miles Laboratories, Inc., Elkhart, IN), 5 $\mathrm{mM}$ glucose, $4 \mathrm{mM}$ sodium lactate, $1 \mathrm{mM}$ alanine, $1 \mathrm{mM}$ sodium butyrate, and $24 \mathrm{mg}$ of collagenase (Type I, Worthington Biochemical Corp., Freehold, NJ) in a siliconized $250-\mathrm{ml}$ Erlenmeyer flask. The flask was gassed with $95 \% \mathrm{O}_{2} / 5 \% \mathrm{CO}_{2}$, sealed, and placed in shaking water bath at $37^{\circ} \mathrm{C}$. The flask was gently shaken for $30-50$ min depending on the activity of the particular lot of collagenase being used. 
At the end of the collagenase treatment period, the flask was removed from the water bath and opened and $75 \mathrm{ml}$ of ice-cold solution A was added. The suspension was then filtered through a strainer to remove any remaining pieces of tissue. The filtrate was then centrifuged in a 50$\mathrm{ml}$ tube in a refrigerated centrifuge at $4^{\circ} \mathrm{C}$ for $2 \mathrm{~min}$ at $30 \mathrm{~g}$ to separate a pellet of intact tubules and glomeruli from lighter subcellular debris that remained largely in the supernatant. The tubule pellet was gently resuspended in fresh solution $A$ and recentrifuged. This pellet was then resuspended in $10 \mathrm{ml}$ of fresh solution A containing 5\% fatty acid-free bovine serum albumin and centrifuged again. The resulting pellet was resuspended in $35 \mathrm{ml}$ of solution A containing 50\% Percoll (Pharmacia Fine Chemicals, Piscataway, NJ), and the suspension was centrifuged for $30 \mathrm{~min}$ at $37,000 \mathrm{~g}$ in a DuPont-Sorvall RC-5 centrifuge (DuPont Instruments, Sorvall Biomedical Div., Newtown, CT). The resulting gradient effectively separated lighter glomeruli and distal tubular segments from more dense proximal tubule segments (17). The layer enriched in proximal tubule segments was removed from the gradient with a Pasteur pipette and washed twice with solution A to remove the Percoll, yielding mostly short lengths of proximal tubules.

Basic procedures for study of the final tubule preparation. The final tubule pellet was resuspended to a concentration of $5-7.5 \mathrm{mg}$ of tubule protein $/ \mathrm{ml}$ in a $95 \% \mathrm{O}_{2} / 5 \% \mathrm{CO}_{2}$ gassed, ice-cold solution of the same electrolyte composition as solution $A$ with the addition of $0.6 \%$ dialyzed dextran (Pharmacia Fine Chemicals T40) (18), $5 \mathrm{mM}$ glucose, $4 \mathrm{mM}$ lactate, $1 \mathrm{mM}$ alanine, and $10 \mathrm{mM}$ butyrate. $4.5-\mathrm{ml}$ aliquots of this tubule suspension were placed in siliconized 25-ml Erlenmeyer flasks which were then gassed with $95 \% \mathrm{O}_{2} / 5 \% \mathrm{CO}_{2}$, sealed, and kept on ice until use. As they were needed for experiments, flasks were placed in a shaking water bath at $37^{\circ} \mathrm{C}$ and were gently shaken for the desired periods of warm incubation.

Measurements of tubule respiration. A sample of tubule suspension was placed in a $1.9-\mathrm{ml}$, sealed, temperature-controlled $\left(37^{\circ} \mathrm{C}\right)$ chamber equipped with a magnetic stirrer and a Clark oxygen electrode (Gilson Medical Electronics, Inc., Middleton, WI), and oxygen consumption was measured under the following conditions: (a) Basal respirationthe respiratory rate in the presence of available substrates without any further additions representing the net result of steady-state energy-requiring processes within the tubules at that point in time; $(b)$ uncoupled respiration-the stimulated rate of respiration occurring in the presence of a supramaximal dose of an uncoupler of mitochondrial respiration, $15 \mu \mathrm{M}$ carbonyl-cyanide- $m$-chlorophenylhydrazone (CCCLP)'; this measures the maximal rate of oxidative metabolism of which the preparation is capable at any given point and can serve as a valuable index both of the utility of available substrates and of the overall integrity of mitochondrial electron transport mechanisms within the tubules; (c) succinate-stimulated uncoupled respiration-the respiratory rate which follows addition of $5 \mathrm{mM}$ sodium succinate during CCCLP uncoupled respiration.

Measurement of tubule electrolyte content. For measurement of total tubule cell cation levels, the tubules were rapidly separated from their suspending medium by gently layering $0.5 \mathrm{ml}$ of tubule suspension into a $1.5-\mathrm{ml}$ microcentrifuge tube on $0.7 \mathrm{ml}$ of bromododecane (Aldrich Chemical Co., Milwaukee, WI), which had previously been layered on $0.2 \mathrm{ml}$ of $275 \mathrm{mM}$ sucrose containing 4\% Ficoll (Pharmacia Fine Chemicals) to increase its density while maintaining isotonicity. The tube was then centrifuged in an Eppendorf microcentrifuge for $30 \mathrm{~s}$ to pellet the tubules in the bottom sucrose layer. The original suspending medium that contained the tubules remained above the bromododecane layer and was then removed as was the bromododecane. Electrolyte levels of the tubules in the bottom sucrose-Ficoll layer were measured by atomic absorption spectroscopy as previously described (19).

Measurement of tubule adenine nucleotides. Tubule suspensions were sampled by two methods to quantify accurately both intracellular and extracellular adenine nucleotides under various conditions. To measure

1. Abbreviations used in this paper: CCCLP, carbonyl-cyanide-m-chlorophenylhydrazone; $N$, oxygen deprivation; $R$, oxygen recovery. total suspension adenine nucleotide levels, $0.4 \mathrm{ml}$ of tubule suspension was added to an equal volume of $12 \%$ trichloroacetic acid (TCA) in a $1.5-\mathrm{ml}$ microcentrifuge tube which was vigorously mixed and then centrifuged. The supernatant was removed from the protein pellet and was neutralized and extracted by mixing with an equal volume of $0.5 \mathrm{M}$ tri$n$-octylamine (Aldrich Chemical Co.) in Freon-113 (Matheson Gas Products, Inc., East Rutherford, NJ) (20). Separation of the Freon and aqueous layers was facilitated by a brief centrifugation. Then the aqueous layer was removed, filtered through $0.45-\mu \mathrm{m}$ nitrocellulose filters, and frozen. To determine intracellular nucleotide levels directly and to measure medium nucleotides, a procedure similar to that utilized for determination of tubule electrolytes was used. $0.4 \mathrm{ml}$ of $12 \%$ TCA in a 1.5$\mathrm{ml}$ microcentrifuge tube were overlaid with $0.7 \mathrm{ml}$ of bromododecane. $0.4 \mathrm{ml}$ of tubule suspension was gently layered on the bromododecane, and the tube was immediately centrifuged for $30 \mathrm{~s}$ in an Eppendorf microcentrifuge to rapidly move the tubules into the TCA layer, leaving the tubule medium as a supernatant. A sample of the supernatant was immediately added to an equal volume of $12 \%$ TCA for determination of medium nucleotide levels; then the remaining supernatant and bromododecane were discarded. The volume of the bottom TCA layer of the centrifuge tube was brought up to $0.8 \mathrm{ml}$ with the medium used for final resuspension of tubules, as described above. This TCA extract was then mixed again and recentrifuged, and the resulting supernatant was separated from the protein pellet. Subsequent steps were identical to those described above for measurement of total suspension nucleotide levels. Recovery of adenine nucleotides by this method was virtually $100 \%$.

Adenine nucleotides were quantified by high performance liquid chromatography at an absorbance of $254 \mathrm{~nm}$ with a Whatman Partisil 10 SAX strong anion-exchange column (Whatman Chemical Separations, Inc., Clifton, $\mathrm{NJ}$ ) and a gradient elution system (21) utilizing $5 \mathrm{mM}$ $\mathrm{NH}_{4} \mathrm{H}_{2} \mathrm{PO}_{4}, \mathrm{pH} 3.0$ (buffer A), and $0.5 \mathrm{M} \mathrm{NH}_{4} \mathrm{H}_{2} \mathrm{PO}_{4}, \mathrm{pH} 4.50$ (buffer $B$ ), at a flow rate of $1.5 \mathrm{ml} / \mathrm{min}$. Samples were initially eluted isocratically with buffer A for $6 \mathrm{~min}$ to elute AMP. The percentage of buffer B was then increased over $30 \mathrm{~min}$ to $50 \%$ to elute ADP. The percentage of buffer B was then further increased over 5 min to $100 \%$ which was continued between 35 and 46 min to elute ATP. The column was then reequilibrated with buffer $A$ for $15 \mathrm{~min}$ before injection of the next sample. Standard curves were generated using pure nucleotides. We have found that this method combines the reproducibility and ease of use of purely isocratic elution methods with the ability to measure all the adenine nucleotides of interest simultaneously on a single sample.

pH measurements. In studies where suspension pHs were measured, the standard oximeter chamber was replaced by a $2.1-\mathrm{ml}$ temperaturecontrolled chamber with ports for both a Clark oxygen electrode and a pH electrode (S900C, Sensorex, Stanton, CA). For measurements of tubule pellet $\mathrm{pH}$ levels, a 6-mm electrode was used (S311A, Beckman Instruments, Inc., Fullerton, CA).

Preparation and study of isolated mitochondria. Kidneys were rapidly removed and placed in ice-cold $275 \mathrm{mM}$ sucrose, and the cortices were promptly dissected, minced, and homogenized in $275 \mathrm{mM}$ sucrose, 1 mM EGTA, $5 \mathrm{mM}$ Tris-HCl, $\mathrm{pH}$ 7.4. Then mitochondria were separated by differential centrifugation exactly as detailed previously (19) except that the final resuspension was made to a concentration of $5 \mathrm{mg}$ protein/ $\mathrm{ml}$ in a solution identical to that used for tubule incubation (see "Basic procedures" section above), and all subsequent experimental procedures exactly paralleled those used for intact tubule studies.

Morphologic studies. Preparations were routinely observed in the fresh state by light microscopy and photographed. 0.4\% trypan blue was used to highlight nonviable cells. For microscopic studies of fixed material, tubules were pelleted, fixed in $0.1 \mathrm{M}$ sodium cacodylate $\mathrm{pH} 7.4,2 \%$ glutaraldehyde, and then processed for light microscopy of semithin sections as previously described (19).

Protein assay. Proteins were quantified by the Lowry assay (22).

Reagents. All reagents used were of the highest grade commercially available. All organic reagents were obtained from Sigma Chemical Co., St. Louis, MO, unless otherwise indicated.

General experimental design. Tubule studies were conducted ac- 
cording to the general protocols outlined in Fig. 1. Washed tubule suspensions were kept at $4^{\circ} \mathrm{C}$ after completion of tubule isolation until samples were needed for particular experiments. All experiments were started by incubating tubules in oxygenated medium at $37^{\circ} \mathrm{C}$ for $15 \mathrm{~min}$. At the end of this period the flasks of tubules were reoxygenated with $95 \% \mathrm{O}_{2} / 5 \% \mathrm{CO}_{2}$ (as a handling control and to allow addition of experimental agents) or were gassed with $95 \% \mathrm{~N}_{2} / 5 \% \mathrm{CO}_{2}$ for $5 \mathrm{~min}$ to remove medium oxygen. The final steady-state level of hypoxia was reached within 2 min of starting $95 \% \mathrm{~N}_{2} / 5 \% \mathrm{CO}_{2} .90 \%$ of the decrease in medium $\mathrm{O}_{2}$ occurred in the first minute.

To produce oxygen deprivation under hypoxic conditions, tubules in flasks which had been gassed with $95 \% \mathrm{~N}_{2} / 5 \% \mathrm{CO}_{2}$ were sealed and maintained in suspension at the usual concentration, $5-7.5 \mathrm{mg}$ of tubule protein $/ \mathrm{ml}$, by shaking the flasks in the water bath in a fashion identical to that used to keep control tubules oxygenated. To study tubules oxygendeprived under conditions more closely simulating the high tubule density present during ischemia in vivo, the contents of a flask $(4.5 \mathrm{ml}$ of tubule suspension) were gassed with $95 \% \mathrm{~N}_{2} / 5 \% \mathrm{CO}_{2}$ for $5 \mathrm{~min}$, then were rapidly transferred to a $15-\mathrm{ml}$ centrifuge tube which was gassed with $95 \% \mathrm{~N}_{2} / 5 \% \mathrm{CO}_{2}$, sealed, and centrifuged at $30 \mathrm{~g}$ for $30-40 \mathrm{~s}$, a time sufficient to pellet all tubules lightly at the bottom of the centrifuge tube. The tube was then incubated without shaking at $37^{\circ} \mathrm{C}$ for the desired duration of oxygen deprivation. At the end of the oxygen deprivation period, these tubules were resuspended in the full volume of incubation medium by gently inverting the tube twice.

Depending on the desired length of hypoxia or ischemia for particular experiments, tubules were oxygen deprived for either 15,30 , or $60 \mathrm{~min}$ timed from the initiation of gassing with $95 \% \mathrm{~N}_{2} / 5 \% \mathrm{CO}_{2}$. After the period of oxygen deprivation, tubules were either sampled for metabolic studies or were reoxygenated with $95 \% \mathrm{O}_{2} / 5 \% \mathrm{CO}_{2}$ (ischemic tubules were transferred back to Erlenmeyer flasks for reoxygenation). After an additional 60 -min period of incubation in oxygenated medium, tubules were sampled for final study.

Statistics. Most studies involved multigroup comparisons and were, therefore, initially assessed by analysis of variance using models accounting for repeated measure designs (BMDP Statistical Software, Los Angeles, CA) (23). Individual group comparisons in these multigroup studies were then made using Scheffe's test for multiple comparisons (24). For experimental designs consisting of only two groups, unpaired or paired Student's $t$ tests with $P<0.05$, two-tailed, considered to be significant were used. For multigroup comparisons among unpaired groups a oneway analysis of variance was utilized.

\section{Results}

Control preparations. The behaviors of three separate groups of tubule preparations studied under control conditions for various

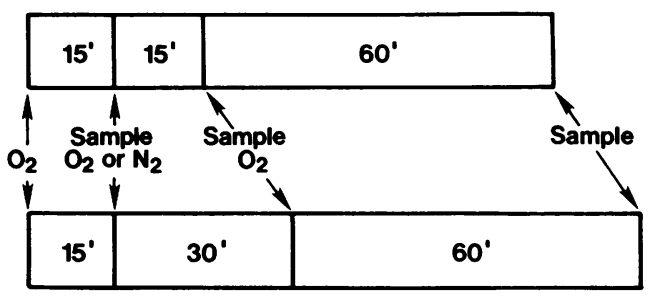

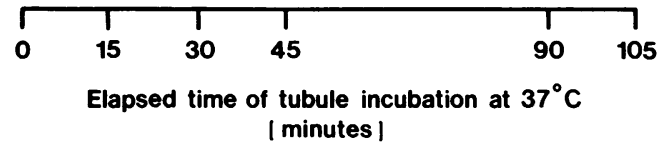

Figure 1. General protocol used for tubule oxygen deprivation manipulations. Studies were also done with 60-min periods of oxygen deprivation followed by $60 \mathrm{~min}$ of recovery for a total study incubation time of $135 \mathrm{~min}$. lengths of incubation time at $37^{\circ} \mathrm{C}$ are summarized in Tables I and II. These groups consist of the same preparations used for the oxygen deprivation studies summarized in Tables III and IV. Average control basal respiratory rates ranged from 39.9 to 45.9 natoms of oxygen/min per $\mathrm{mg}$ of protein and tended to be 5-10\% lower at 90-135 min of incubation than at $15 \mathrm{~min}$. Average CCCLP uncoupled respiratory rates ranged from 127.5 to 154.3 natoms of oxygen/min per $\mathrm{mg}$ of protein in these groups. Lowest uncoupled respiratory rates were seen at $15 \mathrm{~min}$ of incubation, rates peaked at 30-60 min of incubation and then fell off slightly at 90-135 min of incubation, but the absolute changes were small and did not reach statistical significance. Succinate, added after CCCLP, did not further stimulate the respiratory rate in control tubules.

Average $\mathrm{K}^{+}$levels in the cold tubules at the end of the isolation procedure ranged from 137.4 to $147.6 \mathrm{nmol} / \mathrm{mg}$ of protein. $15 \mathrm{~min}$ of incubation at $37^{\circ} \mathrm{C}$ raised cell $\mathrm{K}^{+}$to $298.7-325.6$ $\mathrm{nmol} / \mathrm{mg}$ of protein $(P<0.01$ in all groups). During $105-135$ min of further incubation, cell $\mathrm{K}^{+}$levels tended to increase to average values of $317.2-347.6 \mathrm{nmol} / \mathrm{mg}$ of protein, but none of the differences between cell $\mathrm{K}^{+}$levels at $15 \mathrm{~min}$ and at the longest intervals of incubation at $37^{\circ} \mathrm{C}$ reached significance within individual groups. Cell $\mathrm{Ca}^{++}$levels averaged $20.7-23.9 \mathrm{nmol} / \mathrm{mg}$ of protein in the cold preparations. After $15 \mathrm{~min}$ of incubation at $37^{\circ} \mathrm{C}$ they averaged $18.9-20.2 \mathrm{nmol} / \mathrm{mg}$ of protein, and after $105-135 \mathrm{~min}$ of incubation they averaged $12.0-14.3 \mathrm{nmol} / \mathrm{mg}$ of protein $(P<0.05,15 \mathrm{~min}$ vs. longest duration of incubation in each group). Cell $\mathrm{Mg}^{++}$levels averaged $40.5-49.7 \mathrm{nmol} / \mathrm{mg}$ of protein and did not consistently change during incubation.

The values given for protein recovery indicate the percentage of tubule protein from the total suspension that was recovered in the lower sucrose-Ficoll layer after centrifugation of the tubules through bromododecane to separate them rapidly from their suspending medium for determination of intracellular solute levels without major extracellular space contamination. As detailed further below, this appears to be a very good quantitative index of tubule structural integrity. Average protein recoveries ranged from 82.8 to $104.3 \%$ with most values between 90 and $100 \%$ for these control preparations.

The intracellular adenine nucleotide values given in Tables I and II were obtained by subtracting the levels of adenine nucleotides measured in the tubule suspending medium after tubules were removed by high-speed centrifugation from the adenine nucleotide levels of the original suspension. In control preparations only AMP is present in the medium in amounts, $0.13-0.39 \mathrm{nmol} / \mathrm{mg}$ of protein in the groups studied, that result in substantial corrections to suspension values. Medium ADP levels averaged $0.06-0.15 \mathrm{nmol} / \mathrm{mg}$ of protein while ATP levels were $0.01-0.10 \mathrm{nmol} / \mathrm{mg}$ of protein.

Average intracellular AMP levels were $0.29-0.47 \mathrm{nmol} / \mathrm{mg}$ of protein in cold and 15-min incubated samples and were 0.15 $0.24 \mathrm{nmol} / \mathrm{mg}$ of protein with $105-135 \mathrm{~min}$ of incubation. The differences among AMP levels during incubation did not reach statistical significance within these groups. Average ADP levels ranged from 1.51 to $2.50 \mathrm{nmol} / \mathrm{mg}$ of protein in the cold samples, were $1.12-1.34 \mathrm{nmol} / \mathrm{mg}$ of protein with $15 \mathrm{~min}$ of incubation at $37^{\circ} \mathrm{C}$ and $1.05-1.34 \mathrm{nmol} / \mathrm{mg}$ of protein at $105-135 \mathrm{~min}(P$ $<0.05$ or better, cold samples vs. all durations of incubation at $37^{\circ} \mathrm{C}$ ). Average ATP levels of the cold samples were $2.75-5.22$ $\mathrm{nmol} / \mathrm{mg}$ of protein. They increased sharply with $15 \mathrm{~min}$ of incubation to $5.02-7.00 \mathrm{nmol} / \mathrm{mg}$ of protein $(P<0.01$, all groups) and thereafter, rose more gradually to $6.40-9.67 \mathrm{nmol} /$ 
Table I. Tubule Cell Metabolic Parameters under Control Conditions, Group A*

\begin{tabular}{|c|c|c|c|c|c|c|}
\hline & \multicolumn{6}{|c|}{ Incubation time ( $\mathrm{min})$} \\
\hline & Cold & 15 & 30 & 45 & 90 & 105 \\
\hline \multicolumn{7}{|c|}{ Respiratory rates (natoms oxygen/min per mg protein) } \\
\hline Basal & & $44.7 \pm 1.1$ & $43.5 \pm 0.7$ & $44.1 \pm 2.4$ & $42.3 \pm 1.9$ & $42.0 \pm 2.9$ \\
\hline CCCLP & & $141.2 \pm 8.2$ & $158.3 \pm 7.0$ & $164.3 \pm 8.1$ & $153.5 \pm 5.9$ & $153.5 \pm 9.5$ \\
\hline Succinate & & $122.8 \pm 13.1$ & $146.9 \pm 9.2$ & $152.8 \pm 6.6$ & $146.7 \pm 5.0$ & $147.2 \pm 6.2$ \\
\hline \multicolumn{7}{|c|}{ Cell electrolyte levels ( $\mathrm{nmol} / \mathrm{mg}$ protein) } \\
\hline $\mathbf{K}^{+}$ & $137.4 \pm 14.4$ & $325.6 \pm 11.0$ & $318.9 \pm 12.9$ & $323.3 \pm 7.8$ & $342.3 \pm 14.0$ & $347.6 \pm 8.5$ \\
\hline $\mathrm{Ca}^{++}$ & $23.9 \pm 2.4$ & $18.9 \pm 1.2$ & $17.7 \pm 0.8$ & $16.2 \pm 1.1$ & $13.0 \pm 0.5$ & $13.2 \pm 1.0$ \\
\hline $\mathrm{Mg}^{++}$ & $42.4 \pm 1.5$ & $40.5 \pm 0.9$ & $41.6 \pm 0.6$ & $41.1 \pm 0.6$ & $43.0 \pm 2.0$ & $43.5 \pm 1.9$ \\
\hline \multicolumn{7}{|c|}{ Protein recovery $(\%)$} \\
\hline & $102.3 \pm 2.8$ & $96.6 \pm 2.0$ & $99.4 \pm 0.5$ & $103.0 \pm 1.6$ & $94.1 \pm 2.5$ & $92.4 \pm 7.2$ \\
\hline \multicolumn{7}{|c|}{ Cell adenine nucleotides ( $\mathrm{nmol} / \mathrm{mg}$ protein) } \\
\hline AMP & $0.47 \pm 0.07$ & $0.37 \pm 0.02$ & $0.40 \pm 0.05$ & $0.37 \pm 0.04$ & $0.30 \pm 0.03$ & $0.24 \pm 0.05$ \\
\hline ADP & $2.50 \pm 0.34$ & $1.86 \pm 0.30$ & $1.42 \pm 0.26$ & $1.42 \pm 0.23$ & $1.56 \pm 0.29$ & $1.34 \pm 0.17$ \\
\hline ATP & $5.22 \pm 0.28$ & $7.00 \pm 0.31$ & $8.15 \pm 0.44$ & $9.13 \pm 0.58$ & $9.37 \pm 0.48$ & $9.67 \pm 0.54$ \\
\hline ADN & $8.19 \pm 0.40$ & $8.11 \pm 0.18$ & $8.76 \pm 0.26$ & $9.96 \pm 0.48$ & $11.07 \pm 0.67$ & $11.01 \pm 0.48$ \\
\hline \multicolumn{7}{|c|}{ Medium adenine nucleotides ( $\mathrm{nmol} / \mathrm{mg}$ protein) } \\
\hline AMP & $0.16 \pm 0.02$ & $0.37 \pm 0.07$ & $0.37 \pm 0.08$ & $0.25 \pm 0.04$ & $0.18 \pm 0.03$ & $0.21 \pm 0.05$ \\
\hline ADP & $0.14 \pm 0.02$ & $0.15 \pm 0.02$ & $0.15 \pm 0.01$ & $0.12 \pm 0.02$ & $0.12 \pm 0.01$ & $0.10 \pm 0.01$ \\
\hline ATP & $0.10 \pm 0.04$ & $0.04 \pm 0.01$ & $0.02 \pm 0.01$ & $0.09 \pm 0.05$ & $0.02 \pm 0.01$ & $0.02 \pm 0.01$ \\
\hline $\mathrm{ADN}$ & $0.39 \pm 0.04$ & $0.56 \pm 0.09$ & $0.51 \pm 0.10$ & $0.46 \pm 0.03$ & $0.30 \pm 0.04$ & $0.35 \pm 0.03$ \\
\hline
\end{tabular}

* All values given are means \pm standard error for $n=4$. Cold refers to tubules sampled at the end of the isolation procedure, before warming. Incubation time indicates the length of tubule incubation at $37^{\circ} \mathrm{C}$. ADN, total adenine nucleotides, AMP + ADP + ATP. Other abbreviations are as used in the text.

mg of protein at $105-135$ min of incubation $(P<0.01$ or better vs. $15 \mathrm{~min})$. Total adenine nucleotides behaved similarly to the ATP levels, reflecting the quantitative predominance of that nucleotide. Thus, tubules in suspension studied during up to 135 min of incubation at $37^{\circ} \mathrm{C}$ maintained a predictable, reproducible, and relatively high degree of metabolic stability with regard to basic parameters of oxidative energy metabolism, adenine nucleotides, and intracellular cation homeostasis.

Effects of oxygen deprivation. The response of the preparation to oxygen deprivation and to oxygen deprivation followed by a 60-min recovery period under reoxygenated conditions is summarized in Tables III and IV. The 15- and 30-min hypoxia experiments were done on the same preparations of tubules for which the time control studies are summarized in Table $I$ as group A. The 30- and 60-min ischemia studies were done on the same tubule preparations for which the time control studies are summarized in Table II as groups B and C.

Respiratory rates were measured only after the reoxygenation period (oxygen levels immediately at the end of the oxygen deprivation periods were at the lower limit of detectability of the instrumentation used with all types of oxygen deprivation). Both basal and CCCLP-uncoupled respiratory rates behaved similarly. They were severely depressed relative to time controls after $\mathbf{3 0}$ min of hypoxia $(P<0.01)$ and were moderately depressed after $15 \mathrm{~min}$ of hypoxia $(P<0.01)$ or $60 \mathrm{~min}$ of ischemia $(P<0.01)$. The minimally decreased rates after $30 \mathrm{~min}$ of ischemia were not significantly different from those of time controls in this study. 30-min hypoxic tubules had significantly slower rates than 15-min hypoxic or 30 - or 60 -min ischemic tubules $(P<0.001)$. 60 -min ischemic tubules had significantly lower rates than 30 min ischemic tubules $(P<0.05)$. Ratios of CCCLP-uncoupled rates with succinate to rates without succinate were markedly elevated above time control values (0.9-1.0) after $30 \mathrm{~min}$ of hypoxia $(P<0.01)$ and were minimally but significantly elevated after $60 \mathrm{~min}$ of ischemia $(P<0.01)$. Succinate did not significantly affect CCCLP-uncoupled rates after $15 \mathrm{~min}$ of hypoxia or $30 \mathrm{~min}$ of ischemia.

Data on cell electrolyte levels are available for both the end of the oxygen deprivation period $(\mathrm{N})$ and the end of the recovery period $(\mathrm{R})$. The amounts of protein recovered in the tubule pellets centrifuged through bromododecane and used for determination of cell electrolytes varied markedly as a function of the type of oxygen deprivation. Protein recovery was severely diminished to $<25 \%$ ( $P<0.01$ vs. time controls) at both $\mathrm{N}$ and $\mathrm{R}$ sampling times after $30 \mathrm{~min}$ of hypoxia. With $15 \mathrm{~min}$ of hypoxia or $\mathbf{3 0}$ min of ischemia, protein recovery was not diminished relative to time controls in the $\mathrm{N}$ samples but did decrease moderately in the $\mathrm{R}$ samples $(P<0.05)$. With $60 \mathrm{~min}$ of ischemia, protein recovery was moderately diminished relative to time controls in both $\mathrm{N}$ and $\mathrm{R}$ samples $(P<0.05)$.

Cell $\mathrm{K}^{+}$levels were sharply reduced relative to time controls $(P<0.01)$ at the end of oxygen deprivation. Ischemic tubules tended to have slightly higher $\mathrm{K}^{+}$levels at this point than hypoxic tubules but the differences among the groups were not statistically significant. With reoxygenation, cell $\mathrm{K}^{+}$recovered substantially after $15 \mathrm{~min}$ of hypoxia, $30 \mathrm{~min}$ of hypoxia, or $60 \mathrm{~min}$ of ischemia 
Table II. Tubule Cell Metabolic Parameters under Control Conditions, Groups B and C*

\begin{tabular}{|c|c|c|c|c|c|c|c|c|}
\hline & \multicolumn{4}{|c|}{ Incubation time (min) } & \multicolumn{4}{|c|}{ Incubation time (min) } \\
\hline & Cold & 15 & 45 & 105 & Cold & 15 & 75 & 135 \\
\hline & \multicolumn{4}{|l|}{ Group B } & \multicolumn{4}{|l|}{ Group C } \\
\hline \multicolumn{9}{|c|}{ Respiratory rates (natoms oxygen/min per mg protein) } \\
\hline Basal & - & $45.9 \pm 3.1$ & $44.2 \pm 2.6$ & $39.9 \pm 1.1$ & - & $44.2 \pm 0.8$ & $40.0 \pm 0.9$ & $40.8 \pm 1.0$ \\
\hline CCCLP & - & $127.5 \pm 11.8$ & $157.9 \pm 6.4$ & $139.5 \pm 7.4$ & - & $141.5 \pm 5.7$ & $152.8 \pm 2.3$ & $145.1 \pm 3.1$ \\
\hline Succinate & - & $111.2 \pm 11.5$ & $144.4 \pm 8.4$ & $144.0 \pm 5.3$ & - & $137.6 \pm 7.6$ & $150.8 \pm 3.7$ & $144.5 \pm 3.2$ \\
\hline \multicolumn{9}{|c|}{ Cell electrolyte levels ( $\mathrm{nmol} / \mathrm{mg}$ protein) } \\
\hline $\mathrm{K}^{+}$ & $142.6 \pm 5.0$ & $298.7 \pm 18.5$ & $305.2 \pm 1.0$ & $317.2 \pm 12.8$ & $147.6 \pm 4.8$ & $316.4 \pm 11.0$ & $315.1 \pm 7.9$ & $328.2 \pm 9.5$ \\
\hline $\mathrm{Ca}^{++}$ & $27.4 \pm 3.1$ & $20.2 \pm 1.7$ & $18.4 \pm 2.3$ & $14.3 \pm 1.1$ & $20.7 \pm 0.5$ & $19.2 \pm 0.5$ & $14.6 \pm 0.6$ & $12.3 \pm 0.6$ \\
\hline $\mathbf{M g}^{++}$ & $48.9 \pm 2.0$ & $44.1 \pm 1.0$ & $43.9 \pm 1.3$ & $43.1 \pm 1.2$ & $49.7 \pm 0.5$ & $45.1 \pm 0.6$ & $45.9 \pm 0.8$ & $47.8 \pm 0.7$ \\
\hline \multicolumn{9}{|c|}{ Protein recovery $(\%)$} \\
\hline & $100.4 \pm 3.7$ & $104.3 \pm 2.9$ & $94.6 \pm 3.7$ & $92.3 \pm 4.2$ & $101.8 \pm 0.6$ & $97.3 \pm 2.7$ & $90.1 \pm 4.0$ & $82.8 \pm 1.9$ \\
\hline \multicolumn{9}{|c|}{ Cell adenine nucleotides (nmol/mg protein) } \\
\hline AMP & $0.36 \pm 0.04$ & $0.33 \pm 0.03$ & $0.14 \pm 0.12$ & $0.22 \pm 0.01$ & $0.29 \pm 0.02$ & $0.30 \pm 0.07$ & $0.15 \pm 0.03$ & $0.16 \pm 0.01$ \\
\hline ADP & $1.64 \pm 0.14$ & $1.12 \pm 0.08$ & $0.94 \pm 0.07$ & $1.05 \pm 0.04$ & $1.51 \pm 0.08$ & $1.12 \pm 0.06$ & $1.16 \pm 0.11$ & $1.18 \pm 0.17$ \\
\hline ATP & $2.75 \pm 0.22$ & $5.02 \pm 0.24$ & $6.40 \pm 0.25$ & $7.55 \pm 0.25$ & $3.54 \pm 0.30$ & $5.58 \pm 0.55$ & $7.82 \pm 0.65$ & $8.39 \pm 0.45$ \\
\hline ADN & $4.75 \pm 0.34$ & $6.47 \pm 0.25$ & $7.49 \pm 0.38$ & $8.82 \pm 0.38$ & $5.34 \pm 0.39$ & $7.00 \pm 0.61$ & $9.13 \pm 0.71$ & $9.72 \pm 0.53$ \\
\hline \multicolumn{9}{|c|}{ Medium adenine nucleotides ( $\mathrm{nmol} / \mathrm{mg}$ protein) } \\
\hline AMP & $0.15 \pm 0.05$ & $0.39 \pm 0.02$ & $0.39 \pm 0.12$ & $0.24 \pm 0.04$ & $0.13 \pm 0.02$ & $0.28 \pm 0.04$ & $0.18 \pm 0.01$ & $0.13 \pm 0.01$ \\
\hline ADP & $0.08 \pm 0.01$ & $0.14 \pm 0.01$ & $0.15 \pm 0.03$ & $0.07 \pm 0.02$ & $0.06 \pm 0.01$ & $0.10 \pm 0.00$ & $0.08 \pm 0.01$ & $0.07 \pm 0.01$ \\
\hline ATP & $0.10 \pm 0.01$ & $0.05 \pm 0.00$ & $0.05 \pm 0.00$ & $0.08 \pm 0.05$ & $0.05 \pm 0.01$ & $0.03 \pm 0.00$ & $0.03 \pm 0.01$ & $0.01 \pm 0.00$ \\
\hline ADN & $0.33 \pm 0.06$ & $0.57 \pm 0.01$ & $0.02 \pm 0.20$ & $0.33 \pm 0.03$ & $0.24 \pm 0.02$ & $0.41 \pm 0.04$ & $0.29 \pm 0.01$ & $0.22 \pm 0.01$ \\
\hline
\end{tabular}

* All values are means; group B, $n=4$; group C, $n=6$. Format is otherwise identical to that of Table I.

but remained significantly depressed relative to time controls $(P$ $<0.01$ ). After $30 \mathrm{~min}$ of ischemia and recovery, cell $\mathrm{K}^{+}$was slightly but not significantly lower than in time controls. Of note, the protein recovery results indicate that, after $15 \mathrm{~min}$ of hypoxia, $30 \mathrm{~min}$ of ischemia, and $60 \mathrm{~min}$ of ischemia, electrolytes were being measured on very high fractions of the available tubule material. After $30 \mathrm{~min}$ of hypoxia, however, the protein measurements indicated that electrolytes were only being sampled on $<25 \%$ of the tubule material. As detailed below, morphologic observations on fresh whole suspensions after oxygen deprivation and on the tubule pellets obtained from these preparations after centrifugation through bromododecane indicated that the centrifuged samples contained a higher proportion of relatively intact tubules than the whole suspensions. Thus, the diminished $\mathrm{K}^{+}$ recovery after $30 \mathrm{~min}$ of hypoxia represents that which occurred in the least damaged subpopulation of tubules with this oxygen deprivation condition.

After 15 min of hypoxia, cell $\mathrm{Ca}^{++}$was slightly but not significantly elevated relative to the time control. $\mathrm{Ca}^{++}$did not fall with reoxygenation after $15 \mathrm{~min}$ of hypoxia, and as a result, was significantly elevated relative to the time control at the end of the recovery period $(P<0.05)$. After $30 \mathrm{~min}$ of hypoxia, cell $\mathrm{Ca}^{++}$was substantially elevated relative to the time control $(P$ $<0.01)$ then dropped significantly $(P<0.01, \mathrm{~N}$ vs. $\mathrm{R})$ during reoxygenation to a level approaching and not significantly higher than that seen in the time control. In 30- and 60-min ischemic tubules, cell $\mathrm{Ca}^{++}$levels measured at the end of ischemia were not significantly different from $\mathrm{Ca}^{++}$levels in the time controls and, in fact, tended to be slightly lower. Cell $\mathrm{Ca}^{++}$did not change significantly with reoxygenation in either of the ischemic groups.

Cell $\mathrm{Mg}^{++}$levels were not consistently affected by oxygen deprivation and were similar to those seen in time controls except for a nonsignificant elevation at the end of $30 \mathrm{~min}$ of hypoxia.

Table IV summarizes the behavior of cellular adenine nucleotides in response to the oxygen deprivation maneuvers. The first set of values are the estimated intracellular levels obtained by subtracting from total suspension values the concentrations of adenine nucleotides measured in the suspending medium after precipitation of tubule material by high-speed centrifugation. The second set of values are the intracellular levels directly measured on tubules separated from medium by centrifugation through bromododecane into TCA. The amounts of tubule protein recovered in the lower TCA layer are also given, and, as was the case with the protein recovery in samples used for electrolyte determinations, these values varied with the conditions of oxygen deprivation. The levels of nucleotides measured in the tubule suspending medium after removal of tubules by highspeed centrifugation are also summarized.

Based on the total cell levels estimated from the whole suspension values, all types of oxygen deprivation were associated with increases in cell AMP $(P<0.05$ or better vs. time controls). Highest AMP levels followed $15 \mathrm{~min}$ of hypoxia, intermediate levels followed 30 and $60 \mathrm{~min}$ of ischemia $(P<0.01$ vs. $15 \mathrm{~min}$ of hypoxia) and lowest levels were seen after $30 \mathrm{~min}$ of hypoxia ( $P<0.01$ vs. all other groups). With reoxygenation, the AMP levels returned to values similar to those seen in time controls. 
Table III. Response of Cell Respiratory and Electrolyte Parameters to Oxygen Deprivation*

\begin{tabular}{|c|c|c|c|c|c|c|c|c|}
\hline & \multicolumn{2}{|c|}{ Hypoxia (15 min) } & \multicolumn{2}{|c|}{ Hypoxia (30 min) } & \multicolumn{2}{|c|}{ Ischemia (30 min) } & \multicolumn{2}{|c|}{ Ischemia (60 min) } \\
\hline & $\mathbf{N}$ & $\mathbf{R}$ & $\mathbf{N}$ & $\mathbf{R}$ & $\mathbf{N}$ & $\mathbf{R}$ & $\mathbf{N}$ & $\mathbf{R}$ \\
\hline \multicolumn{9}{|c|}{ Respiratory rates (natoms oxygen/min per mg protein) } \\
\hline Basal & - & $28.9 \pm 3.6$ & - & $11.2 \pm 1.3$ & - & $34.2 \pm 2.4$ & - & $25.3 \pm 1.2$ \\
\hline CCCLP & - & $95.5 \pm 14.9$ & - & $30.9 \pm 4.6$ & - & $124.5 \pm 7.5$ & - & $88.3 \pm 9.2$ \\
\hline Succinate & - & $103.4 \pm 7.9$ & - & $85.3 \pm 3.8$ & - & $127.3 \pm 6.7$ & - & $99.6 \pm 6.1$ \\
\hline $\mathrm{S} / \mathrm{C}$ & - & $1.13 \pm 0.09$ & - & $2.94 \pm 0.32$ & - & $1.02 \pm 0.01$ & - & $1.16 \pm 0.05$ \\
\hline \multicolumn{9}{|c|}{ Cell electrolyte levels ( $\mathrm{nmol} / \mathrm{mg}$ protein) } \\
\hline $\mathbf{K}^{+}$ & $84.4 \pm 11.8$ & $279.2 \pm 25.7$ & $98.5 \pm 20.1$ & $229.8 \pm 17.1$ & $113.6 \pm 4.4$ & $293.2 \pm 17.5$ & $124.1 \pm 7.4$ & $277.6 \pm 14.6$ \\
\hline $\mathrm{Ca}^{++}$ & $20.6 \pm 2.0$ & $19.5 \pm 1.3$ & $30.4 \pm 4.0$ & $17.6 \pm 1.2$ & $15.6 \pm 0.8$ & $14.7 \pm 1.4$ & $13.1 \pm 0.4$ & $13.5 \pm 0.7$ \\
\hline $\mathbf{M g}^{++}$ & $39.1 \pm 1.2$ & $43.2 \pm 2.3$ & $52.6 \pm 9.4$ & $38.8 \pm 4.6$ & $39.6 \pm 1.5$ & $41.4 \pm 1.4$ & $42.5 \pm 0.9$ & $43.5 \pm 1.1$ \\
\hline \multicolumn{9}{|c|}{ Protein recovery (\%) } \\
\hline & $97.5 \pm 2.7$ & $71.5 \pm 3.9$ & $22.4 \pm 6.7$ & $22.5 \pm 4.8$ & $95.6 \pm 4.8$ & $85.7 \pm 2.7$ & $76.8 \pm 2.7$ & $75.2 \pm 2.3$ \\
\hline
\end{tabular}

* All values are means \pm standard error, 15 and 30 min of hypoxia, $n=4 ; 30$ min of ischemia, $n=4 ; 60$ min of ischemia, $n=6$. Samples in columns labeled $\mathrm{N}$ were taken at the end of the indicated period of oxygen deprivation, before reoxygenation. Samples in columns labeled $\mathrm{R}$ were taken after the indicated period of oxygen deprivation plus $60 \mathrm{~min}$ of additional incubation under $95 \% \mathrm{O}_{2} / 5 \% \mathrm{CO}_{2}$. S/C indicates the ratio of CCCLP uncoupled respiration in the presence of $5.0 \mathrm{mM}$ succinate to CCCLP uncoupled respiration in the absence of succinate.

ATP levels were strikingly reduced at the end of oxygen deprivation ( $P<0.01, \mathrm{~N}$ preparations vs. time controls, all groups). Lowest absolute levels were seen after $30 \mathrm{~min}$ of hypoxia and $60 \mathrm{~min}$ of ischemia $(P<0.01$ vs. $15 \mathrm{~min}$ of hypoxia and $30 \mathrm{~min}$ of ischemia). ATP levels recovered with reoxygenation to values only slightly less than those seen in time controls after $15 \mathrm{~min}$ of hypoxia and $30 \mathrm{~min}$ of ischemia, recovered less well but still substantially after $60 \mathrm{~min}$ of ischemia, and recovered only modestly after $30 \mathrm{~min}$ of hypoxia (all R preparations $P<0.05$ or better vs. time controls and $P<0.05$ or better vs. corresponding N preparations, $P<0.01,15 \mathrm{~min}$ of hypoxia, $30 \mathrm{~min}$ of ischemia, and $60 \mathrm{~min}$ of ischemia vs. $30 \mathrm{~min}$ of hypoxia). Total adenine nucleotide levels were significantly reduced at the end of all oxygen deprivation maneuvers $(P<0.01$ vs. time controls) with the mildest changes seen after $15 \mathrm{~min}$ of hypoxia, moderate changes after 30 and $60 \mathrm{~min}$ of ischemia $(P<0.01$ vs. $15 \mathrm{~min}$ of hypoxia) and the most severe changes seen after $30 \mathrm{~min}$ of hypoxia $(P<0.01$ vs. all other groups). Total adenine nucleotides did not significantly increase during recovery in either of the hypoxia groups but did increase significantly compared to $\mathrm{N}$ values $(P<0.01)$ in both ischemia groups.

Intracellular AMP levels measured immediately at the end

Table IV. Response of Cell Adenine Nucleotides to Oxygen Deprivation*

\begin{tabular}{|c|c|c|c|c|c|c|c|c|}
\hline & \multicolumn{2}{|c|}{ Hypoxia (15 min) } & \multicolumn{2}{|c|}{ Hypoxia (30 min) } & \multicolumn{2}{|c|}{ Ischemia (30 min) } & \multicolumn{2}{|c|}{ Ischemia (60 min) } \\
\hline & $\mathbf{N}$ & $\mathbf{R}$ & $\mathbf{N}$ & $\mathbf{R}$ & $\mathbf{N}$ & $\mathbf{R}$ & $\mathbf{N}$ & $\mathbf{R}$ \\
\hline \multicolumn{9}{|c|}{ Intracellular levels estimated from total suspension and medium levels ( $\mathrm{nmol} / \mathrm{mg} \mathrm{protein})$} \\
\hline AMP & $4.00 \pm 0.27$ & $0.34 \pm 0.04$ & $0.84 \pm 0.24$ & $0.15 \pm 0.01$ & $2.38 \pm 0.33$ & $0.20 \pm 0.01$ & $2.22 \pm 0.18$ & $0.18 \pm 0.02$ \\
\hline ADP & $1.80 \pm 0.21$ & $1.00 \pm 0.15$ & $0.76 \pm 0.17$ & $0.38 \pm 0.04$ & $1.24 \pm 0.14$ & $0.90 \pm 0.06$ & $0.72 \pm 0.03$ & $0.86 \pm 0.08$ \\
\hline ATP & $0.72 \pm 0.12$ & $5.77 \pm 0.95$ & $0.28 \pm 0.05$ & $1.58 \pm 0.27$ & $0.81 \pm 0.11$ & $6.00 \pm 0.34$ & $0.34 \pm 0.02$ & $4.50 \pm 0.50$ \\
\hline ADN & $6.51 \pm 0.38$ & $7.11 \pm 1.04$ & $1.89 \pm 0.23$ & $2.11 \pm 0.30$ & $4.42 \pm 0.16$ & $7.11 \pm 0.34$ & $3.28 \pm 0.21$ & $5.55 \pm 0.51$ \\
\hline \multicolumn{9}{|c|}{ Levels in tubules pelleted by centrifugation through bromododecane ( $\mathrm{nmol} / \mathrm{mg} \mathrm{protein})$} \\
\hline AMP & $1.40 \pm 0.13$ & $0.64 \pm 0.30$ & $0.74 \pm 0.06$ & $0.26 \pm 0.01$ & $0.82 \pm 0.07$ & $0.25 \pm 0.02$ & $0.83 \pm 0.11$ & $0.20 \pm 0.01$ \\
\hline ADP & $2.79 \pm 0.34$ & $1.34 \pm 0.26$ & $1.38 \pm 0.18$ & $1.15 \pm 0.21$ & $1.54 \pm 0.13$ & $1.02 \pm 0.06$ & $1.16 \pm 0.06$ & $0.91 \pm 0.05$ \\
\hline ATP & $3.52 \pm 0.29$ & $6.34 \pm 0.87$ & $1.84 \pm 0.29$ & $5.84 \pm 1.18$ & $2.63 \pm 0.19$ & $6.62 \pm 0.29$ & $1.64 \pm 0.13$ & $4.86 \pm 0.48$ \\
\hline $\mathrm{ADN}$ & $7.71 \pm 0.45$ & $8.32 \pm 0.79$ & $3.96 \pm 0.36$ & $7.25 \pm 1.30$ & $4.98 \pm 0.38$ & $7.89 \pm 0.29$ & $3.63 \pm 0.23$ & $5.97 \pm 0.48$ \\
\hline \multicolumn{9}{|c|}{ Protein recovery $(\%)$} \\
\hline & $87.0 \pm 12.5$ & $89.1 \pm 6.5$ & $25.0 \pm 8.0$ & $22.4 \pm 1.8$ & $95.3 \pm 5.4$ & $85.0 \pm 5.1$ & $73.3 \pm 1.7$ & $70.2 \pm 2.1$ \\
\hline \multicolumn{9}{|c|}{ Medium levels (nmol/mg protein) } \\
\hline AMP & $1.33 \pm 0.14$ & $0.26 \pm 0.06$ & $2.72 \pm 0.41$ & $0.18 \pm 0.01$ & $0.45 \pm 0.05$ & $0.18 \pm 0.01$ & $0.31 \pm 0.02$ & $0.16 \pm 0.02$ \\
\hline ADP & $0.13 \pm 0.02$ & $0.09 \pm 0.01$ & $0.24 \pm 0.01$ & $0.07 \pm 0.01$ & $0.09 \pm 0.01$ & $0.08 \pm 0.00$ & $0.06 \pm 0.00$ & $0.06 \pm 0.00$ \\
\hline ATP & $0.02 \pm 0.01$ & $0.01 \pm 0.01$ & $0.04 \pm 0.02$ & $0.02 \pm 0.01$ & $0.05 \pm 0.02$ & $0.01 \pm 0.00$ & $0.02 \pm 0.00$ & $0.01 \pm 0.00$ \\
\hline
\end{tabular}

* All values are means \pm standard error. Groups and format of table are otherwise identical to Table III. 
of the oxygen deprivation on tubules separated from their medium by centrifugation through bromododecane were significantly lower $(P<0.01$ for all groups except $30 \mathrm{~min}$ of hypoxia) than those estimated from total suspension and medium levels. ADP and ATP levels were higher $(P<0.05$ or better for all groups) than the levels estimated for the total suspension. Total adenine nucleotide levels at the end of oxygen deprivation were significantly higher in separated tubules than in the total suspensions after $30 \mathrm{~min}$ of hypoxia $(P<0.01)$ but did not significantly differ from total suspension values in the other groups. The decreases of AMP levels and increases in ATP levels without changes in total adenine nucleotides at the end of oxygen deprivation in the bromododecane-centrifuged tubules from groups with mild injury suggest that sufficient oxygenation of these preparations occurred during centrifugation to allow some resumption of ATP synthesis. The absence of such an effect after 30 min of hypoxia is likely due to the more severe injury present in that group. Thus, the adenine nucleotide levels of the tubules separated by centrifugation through bromododecane at the end of hypoxia reflect the state of cell adenine nucleotide metabolism during oxygen deprivation less accurately than estimates based on total suspension and medium values.

The differences for most nucleotide parameters between total suspension and centrifuged sample levels at the end of the recovery period, a time when all samples are fully oxygenated, were minimal and were not statistically significant in mildly injured tubules (15-min hypoxic, 30- or 60 -min ischemic), a situation identical to that seen in the control preparations. The differences after recovery between nucleotide levels in separated tubules and total suspensions for severely injured tubules, i.e., those subjected to $30 \mathrm{~min}$ of hypoxia, were striking $(P<0.01$ for all nucleotide parameters except AMP). These observations are consistent with the protein recovery and electrolyte data suggesting that the bromododecane centrifugation separates a more intact subpopulation of tubules from the total suspension under conditions where widespread injury has occurred.

The experiments comparing modes of oxygen deprivation, which are summarized in Tables III and IV, were done on dif- ferent groups of tubule preparations. Although overall control tubule function (as summarized in Tables I and II) and the response of the preparation to various maneuvers were relatively constant, we felt it was desirable to assess the response of tubules to $30 \mathrm{~min}$ of ischemia and $30 \mathrm{~min}$ of hypoxia simultaneously in the same preparations. Furthermore, tubules subjected to simulated ischemia differ from those subjected to hypoxia in that they are not agitated during the period of oxygen deprivation. Because the extent to which such tubule preparations are stirred has been shown to influence their integrity (8), we included in this series of experiments an oxygen deprivation maneuver in which the gas atmosphere of the incubation flask was changed to $95 \% \mathrm{~N}_{2} / 5 \% \mathrm{CO}_{2}$ as routinely done. The tubules were then allowed to settle as a loose diffuse layer to the bottom of the flask and to remain without stirring during the entire period of oxygen deprivation. These tubules are indicated as "not shaken" (NS) preparations. The results of measurements of several of the key metabolic parameters in this experimental group are summarized in Table $\mathrm{V}$ and indicate that the markedly different responses to ischemia and hypoxia were fully retained when both maneuvers were studied in the same preparation. Furthermore, tubules that were not shaken during hypoxia behaved in a fashion indistinguishable from those which were shaken, indicating that the absence of mechanical agitation did not account for the protection seen in the ischemic tubules.

Table VI summarizes the results of two studies designed to better define the basis for the tubule response to addition of succinate. In the first study tubules were either oxygenated for $105 \mathrm{~min}$ or were oxygenated for $15 \mathrm{~min}$, made hypoxic for 30 $\mathrm{min}$, and then reoxygenated for $60 \mathrm{~min}$, as in the standard experimental protocol. Then they were studied in the oximeter with succinate added after CCCLP as well as with succinate added during basal respiration before CCCLP. When succinate was added after CCCLP, the usual pattern of effects was seen, in that respiration was not stimulated in time control oxygenated tubules but was strikingly stimulated in the posthypoxic tubules $(P=0.01)$. When succinate was added during basal respiration to control oxygenated tubules, respiration increased to

Table V. Response of Cellular Metabolic Parameters to Oxygen Deprivation, Paired Studies*

\begin{tabular}{|c|c|c|c|c|c|c|}
\hline & \multicolumn{2}{|c|}{ Hypoxia (30 min) } & \multicolumn{2}{|c|}{ Hypoxia, NS (30 min)‡ } & \multicolumn{2}{|c|}{ Ischemia (30 min) } \\
\hline & $\mathbf{N}$ & $\mathbf{R}$ & $\mathbf{N}$ & $\mathbf{R}$ & $\mathbf{N}$ & $\mathbf{R}$ \\
\hline \multicolumn{7}{|c|}{ Respiratory rate (natoms oxygen $/ \mathrm{min} / \mathrm{mg}$ protein) } \\
\hline CCCLP & - & $32.5 \pm 3.2$ & - & $25.2 \pm 5.0$ & - & $140.0 \pm 11.1$ \\
\hline \multicolumn{7}{|c|}{ Cell electrolyte levels $(\mathrm{nmol} / \mathrm{mg} / \mathrm{protein})$} \\
\hline $\mathrm{K}^{+}$ & $63.5 \pm 4.9$ & $214.8 \pm 13.0$ & $92.6 \pm 16.8$ & $212.3 \pm 6.5$ & $113.0 \pm 3.8 \S$ & $319.8 \pm 7.5^{\prime \prime}$ \\
\hline $\mathrm{Ca}^{++}$ & $27.0 \pm 2.5$ & $26.7 \pm 3.5$ & $26.0 \pm 3.1$ & $20.3 \pm 5.2$ & $15.3 \pm 0.9^{\prime \prime}$ & $17.9 \pm 2.0$ \\
\hline \multicolumn{7}{|c|}{ Protein recovery $(\%)$} \\
\hline & $29.3 \pm 2.4$ & $28.4 \pm 2.4$ & $21.4 \pm 7.0$ & $20.2 \pm 6.2$ & $92.8 \pm 1.6^{11}$ & $84.3 \pm 3.8^{11}$ \\
\hline \multicolumn{7}{|c|}{ Cell adenine nucleotides estimated from total suspension and medium levels ( $\mathrm{nmol} / \mathrm{mg} \mathrm{protein})$} \\
\hline AMP & $1.58 \pm 0.19$ & $0.17 \pm 0.01$ & $1.29 \pm 0.18$ & $0.18 \pm 0.04$ & $3.58 \pm 0.19^{\prime \prime}$ & $0.30 \pm 0.03$ \\
\hline ATP & $0.32 \pm 0.03$ & $1.70 \pm 0.21$ & $0.26 \pm 0.04$ & $1.16 \pm 0.27$ & $0.49 \pm 0.04$ & $7.11 \pm 0.44^{11}$ \\
\hline
\end{tabular}

* All values are means \pm standard error; $30 \mathrm{~min}$ of hypoxia and $30 \mathrm{~min}$ of ischemia, $n=7 ; 30 \mathrm{~min}$ of hypoxia (NS), $n=4$. Format of table is otherwise identical to that of Tables III and IV. $¥$ NS, not shaken. $\S P<0.05$ or better vs. 30 min of hypoxia and 30 min of hypoxia (NS). " $P$ $<0.01$ vs. $30 \mathrm{~min}$ of hypoxia and $30 \mathrm{~min}$ hypoxia (NS). 
Table VI. Respiratory Effects of Succinate*

\begin{tabular}{|c|c|c|c|c|c|}
\hline Study & Group & Basal & Succinate & CCCLP & Succinate \\
\hline \multicolumn{6}{|c|}{ natoms oxygen/min per mg protein } \\
\hline 105-min oxygenated & $\int A$ & $53.3 \pm 3.9$ & - & $151.1 \pm 9.4$ & $151.1 \pm 9.4$ \\
\hline tubules & B & $56.7 \pm 2.5$ & $63.9 \pm 3.3$ & $147.3 \pm 5.0$ & - \\
\hline 30-min Hypoxic $+60-\min$ & $\int A$ & $18.5 \pm 1.9$ & - & $44.4 \pm 4.6$ & $82.6 \pm 10.9$ \\
\hline reoxygenated tubules & $\{\mathrm{B}$ & $20.1 \pm 1.6$ & $57.0 \pm 8.1$ & $77.5 \pm 8.6$ & - \\
\hline $\begin{array}{l}\text { 105-min oxygenated } \\
\text { isolated mitochondria }\end{array}$ & A & $6.5 \pm 0.6$ & - & $13.1 \pm 2.4$ & $170.8 \pm 15.0$ \\
\hline
\end{tabular}

* All values are means \pm standard error; $n=5$ for tubule studies; $n=4$ for mitochondrial studies. In groups labeled A, 5 mM succinate was added while CCCLP uncoupled respiration was under way. In groups labeled B, succinate was added during basal respiration.

$112.6 \pm 2.8 \%$ of basal rates $(P<0.02$, succinate vs. basal rate). A much larger stimulation of basal rates, $298.6 \pm 5.7 \%$, was seen when succinate was added to posthypoxic tubules $(P=0.02$, succinate vs. basal rate, $P<0.01$, relative stimulation in control vs. posthypoxic tubules). Although the relative stimulation of respiration when succinate was added to injured tubule preparations during basal respiration tended to be higher than the relative simulation seen when it was added during CCCLP-uncoupled respiration (186.1 $\pm 11.2 \%)$, the difference did not reach statistical significance. In both control and injured tubules, the final respiratory rates measured with both succinate and CCCLP present were the same irrespective of the order of addition of the agents and these rates were significantly lower in posthypoxic tubules than in time controls $(P<0.01)$.

In the second study summarized in Table VI, isolated rabbit renal cortical mitochondria were incubated under control oxygenated conditions exactly the same as those used to incubate the intact tubules, thus simulating the conditions to which free mitochondria are exposed in the injured tubule preparations during the reoxygenation period. Basal respiratory rates were extremely low and were moderately stimulated by CCCLP ( $P$ $=0.05)$. Subsequent addition of succinate, however, led to a striking stimulation of respiration $(P<0.01)$.

Effects of $p H$. In establishing the experimental system and routinely monitoring it to assure constancy of experimental variables, we had confirmed that regassing the tubule suspension with $95 \% \mathrm{~N}_{2} / 5 \% \mathrm{CO}_{2}$ did not affect its $\mathrm{pH}$, which was maintained at 7.40-7.45. This was expected given the $25 \mathrm{mM} \mathrm{HCO}_{3}^{-}$present in the medium, the $5 \% \mathrm{CO}_{2}$ with $\mathrm{N}_{2}$ in the gas phase, and the relatively small amount of tubule material relative to suspending medium volume. Tubule suspension $\mathrm{pH}$ values averaged $0.1 \pm 0.02 \mathrm{pH}$ units less than similarly incubated suspending medium without tubules $(n=10, P<0.01)$. Tubule suspensions incubated for $30 \mathrm{~min}$ under $95 \% \mathrm{~N}_{2} / 5 \% \mathrm{CO}_{2}$ had suspension pHs which were $0.04 \pm 0.02 \mathrm{pH}$ units greater than paired samples maintained under $95 \% \mathrm{O}_{2} / 5 \% \mathrm{CO}_{2}(n=10, P<0.05)$. It was possible, though, that, when the tubules were pelleted to a much higher density relative to surrounding medium to produce the simulated ischemic conditions, their metabolic processes could result in more substantial alterations of $\mathrm{pH}$ during oxygen deprivation. To test this, a small-tipped $\mathrm{pH}$ electrode was placed in the center of the centrifuged pellet used to produce the ischemic conditions at the start of the oxygen deprivation period. Results of a typical experiment are illustrated in Fig. 2. The first stable pH measurement obtainable after the $30 \mathrm{~s}$ necessary to centrifuge the pellet is already reduced relative to the overlying suspending medium. Thereafter, $\mathrm{pH}$ drops at a steadily decreasing rate during 20-30 min after which it stabilizes. When, after $60 \mathrm{~min}$, the $\mathrm{pH}$ electrode is pulled out of the pellet into the medium just overlying it, the normal medium $\mathrm{pH}$ is then again measured. In six experiments, pellet $\mathrm{pH}$ had stabilized at an average value of $6.96 \pm 04$ by the end of $60 \mathrm{~min}$ of incubation. The average $\mathrm{pH}$ in the medium overlying these samples was $7.42 \pm .00(P<0.001)$.

To test whether such a fall in pH could account for the differences in response to oxygen deprivation between ischemic and hypoxic tubules, tubules were subjected to $30 \mathrm{~min}$ of hypoxia at a wide range of $\mathrm{pHs}$ produced by adding $\mathrm{HCl}$ to the tubule suspensions at the initiation of hypoxia. Sodium bicarbonate was then added at the end of hypoxia to restore the normal suspension $\mathrm{pH}$ and fully simulate the conditions of study utilized for the ischemic pellets which are resuspended in the normal incubation medium at the end of oxygen deprivation. Time control studies in which tubules were subjected to the same $\mathrm{pH}$ manipulations as the hypoxic tubules were also done for every preparation.

The effects of $\mathrm{pH}$ manipulation on behavior of various metabolic parameters in the time control studies are summarized in Table VII. The tubules from which these data were generated

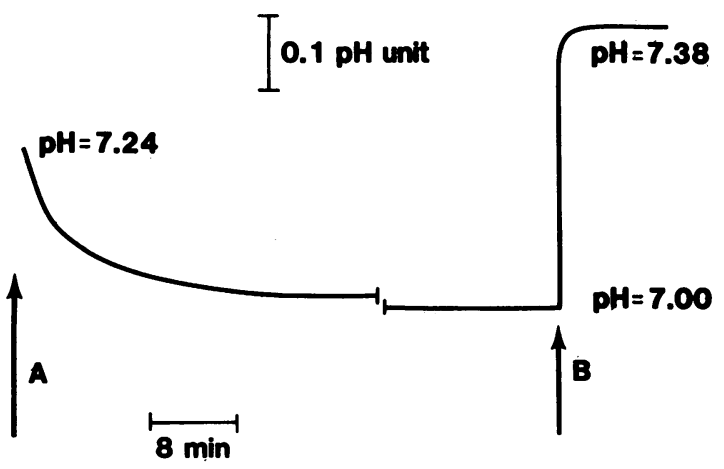

Figure 2. Typical pH response tracing from tubules subjected to oxygen deprivation as lightly centrifuged pellets. The tubule suspension was gassed with $95 \% \mathrm{~N}_{2} / 5 \% \mathrm{CO}_{2}$ and centrifuged for $30 \mathrm{~s}$ at $30 \mathrm{~g}$. Then the pH electrode was placed in the pellet (point $A$ ), and the tube was sealed and incubated at $37^{\circ} \mathrm{C}$. After $60 \mathrm{~min}$, at point $B$, the electrode was gently lifted out of the pellet into the medium just overlying it. 
were initially incubated for $15 \mathrm{~min}$ at $37^{\circ} \mathrm{C}$. Then varying amounts of $\mathrm{HCl}$ were added to lower the medium $\mathrm{pH}$ to as low as 6.41 and incubation was continued for an additional $30 \mathrm{~min}$ at the end of which time the tubules were sampled. To simplify presentation of these control data they are tabulated in Table VII as mean values for groups of tubules with $\mathrm{pH}$ levels at the extremes of the range studied, i.e., $>7.3$ (includes mainly preparations which did not receive $\mathrm{HCl}, n=15)$ and $<6.9(n=11)$. Additionally, to summarize succinctly the behavior of each parameter over the full range of $\mathrm{pH}$ values assessed, the correlation between values for each metabolic parameter and medium $\mathrm{pH}$ for the entire group of tubule preparations studied is given. Trends toward mild reductions in both basal and CCCLP-uncoupled respiratory rates were seen as $\mathrm{pH}$ was decreased; however, the differences reached significance only in comparing CCCLP uncoupled rates in tubules studied at $\mathrm{pH}<6.9$ to those studied at $\mathrm{pH}>7.3$. Tubule $\mathrm{K}^{+}$, protein recovery, and ATP levels were not affected by the $\mathrm{pH}$ manipulations. Tubule cell $\mathrm{Ca}^{++}$fell significantly as medium $\mathrm{pH}$ was reduced. This effect was significant both in comparing tubules at the extremes of the $\mathrm{pH}$ range studied and as an overall negative correlation between cell $\mathrm{Ca}^{++}$and medium $\mathrm{pH}$ across the entire range of $\mathrm{pHs}$ studied.

The effects of incubation medium $\mathrm{pH}$ on hypoxic tubules are illustrated in Figs. 3-10. Fig. 3 summarizes the effects of $\mathrm{pH}$ during hypoxia on CCCLP uncoupled respiratory rates measured at the end of the reoxygenation recovery period. A virtually linear inverse relationship between $\mathrm{pH}$ and respiratory rate is seen $(r$ $=-.917, P<0.01)$. Fig. 3 also illustrates the effects of succinate

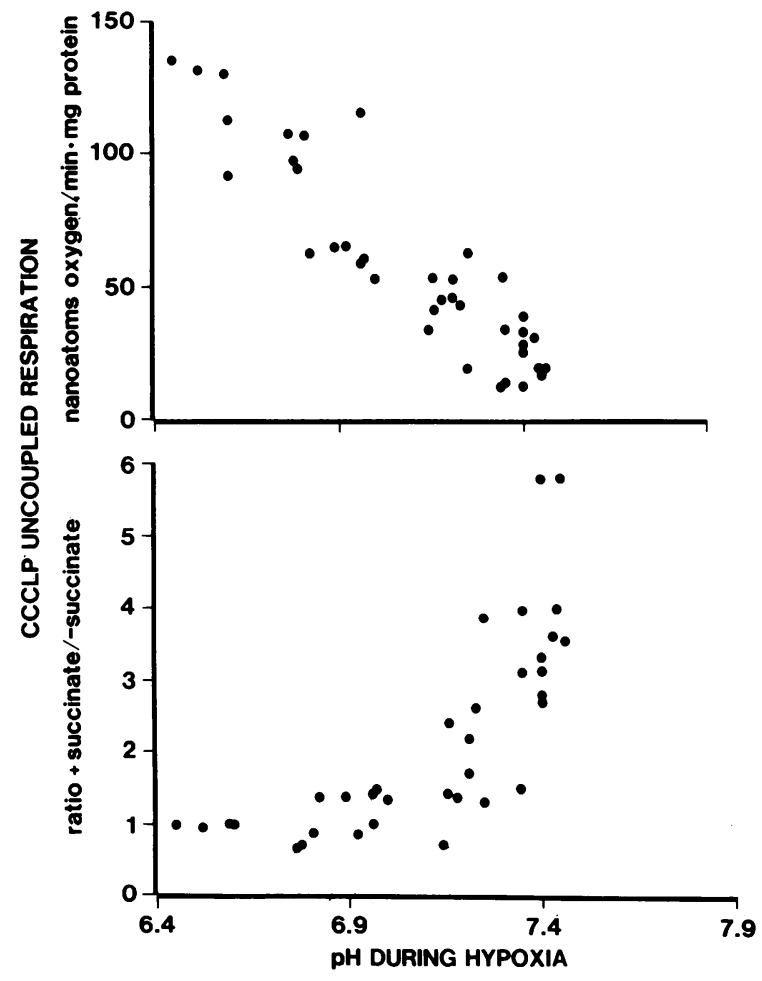

Figure 3. CCCLP-uncoupled respiratory rates (upper panel) and ratios of CCCLP uncoupled respiration in the presence of $5 \mathrm{mM}$ succinate to rates in the absence of succinate (lower panel) at the end of $30 \mathrm{~min}$ of hypoxia followed by $60 \mathrm{~min}$ of reoxygenation as a function of medium $\mathrm{pH}$ maintained during hypoxia. Each point represents the result of a single experiment. on CCCLP-uncoupled respiration. Substantial stimulation by succinate of CCCLP-uncoupled respiration occurred only in tubules subjected to hypoxia at pH levels above 7.0.

Fig. 4 summarizes the relationships between protein recovery at the end of hypoxia and hypoxia plus reoxygenation and the medium pH maintained during hypoxia. Protein recovery is maintained at virtually $100 \%$ at the end of hypoxia until pHs exceed about 7.0 and, thereafter, it falls off sharply. With hypoxia plus reoxygenation, a similar relationship is observed but the best recoveries are somewhat lower than those seen at the end of hypoxia because of small decreases in protein recovery during reoxygenation in the least-injured tubules.

Fig. 5 illustrates the behavior of cell $\mathrm{K}^{+} . \mathrm{K}^{+}$levels at the end of hypoxia did not vary substantially except for being slightly higher at the lowest $\mathrm{pHs}$ tested. With reoxygenation, $\mathrm{K}^{+}$rose toward, but did not consistently reach control levels and showed a moderate but significant inverse correlation with the $\mathrm{pH}$ maintained during hypoxia $(r=0.654, P<0.01)$.

Tubule $\mathrm{Ca}^{++}$levels are summarized in Fig. 6. They were elevated at the end of hypoxia relative to time controls in samples whose pHs were maintained above about 7.0 during hypoxia. With hypoxia + reoxygenation, the effects of $\mathrm{pH}$ during hypoxia were less marked although higher pHs were still associated with higher $\mathrm{Ca}^{++}$levels. These relationships are further clarified in Fig. 7, which shows that, when $\mathrm{Ca}^{++}$was maintained in the normal range during hypoxia, it generally rose with reoxygen-

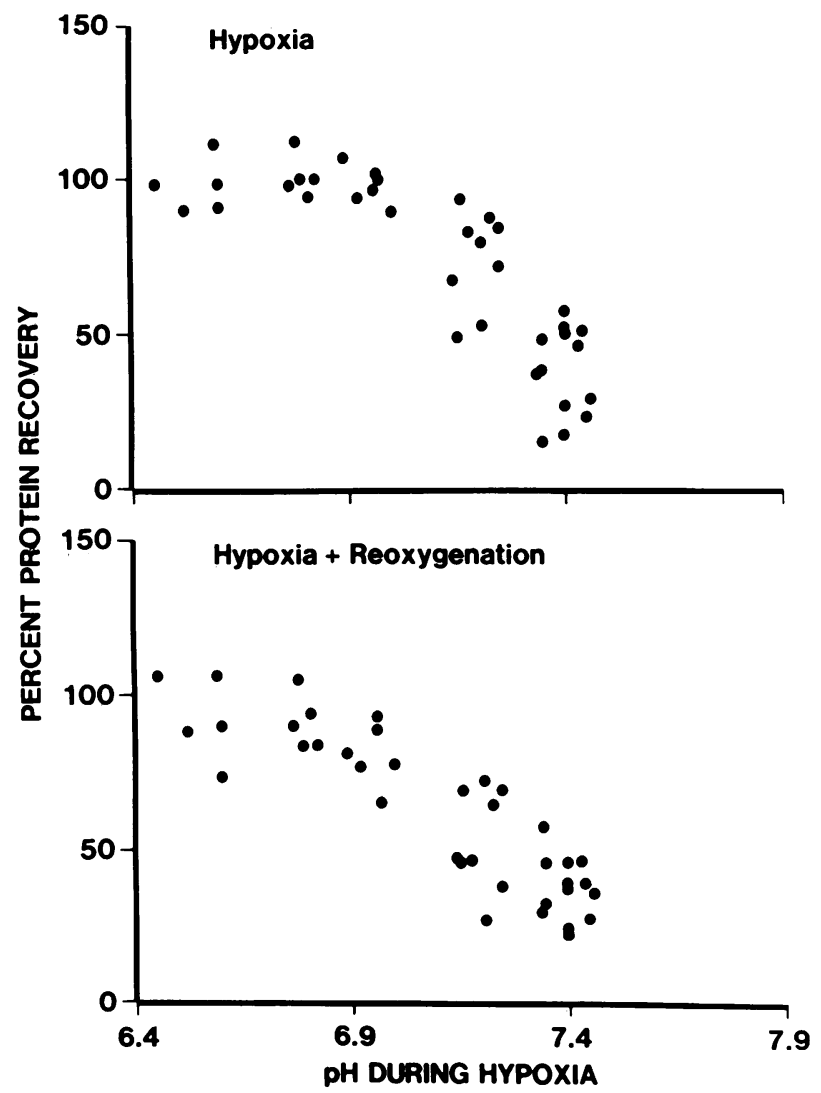

Figure 4. Percent of suspension protein recovered in pellets obtained by centrifugation through bromododecane as a function of suspension pH maintained during 30 min of hypoxia. (Upper panel) Values measured at the end of hypoxia. (Lower panel) Values after hypoxia plus $60 \mathrm{~min}$ of reoxygenation. 


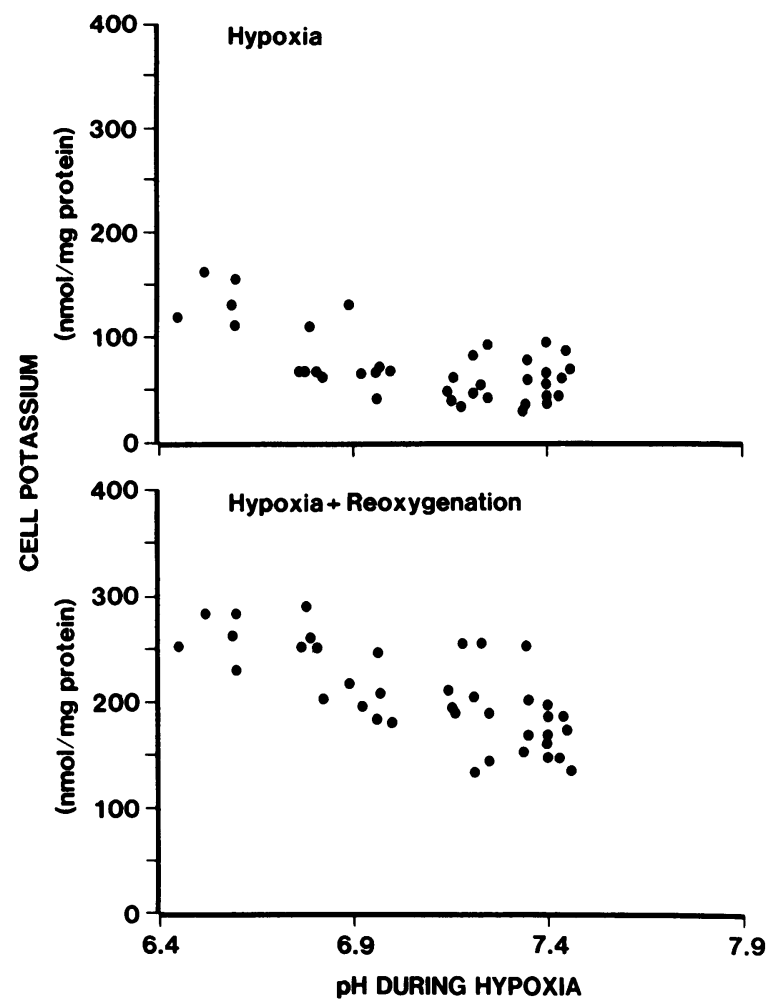

Figure 5. Cell $\mathrm{K}^{+}$as a function of suspension $\mathrm{pH}$ maintained during 30 min of hypoxia. (Upper panel) Values measured at the end of hypoxia. (Lower panel) Values after hypoxia plus $60 \mathrm{~min}$ of reoxygenation.

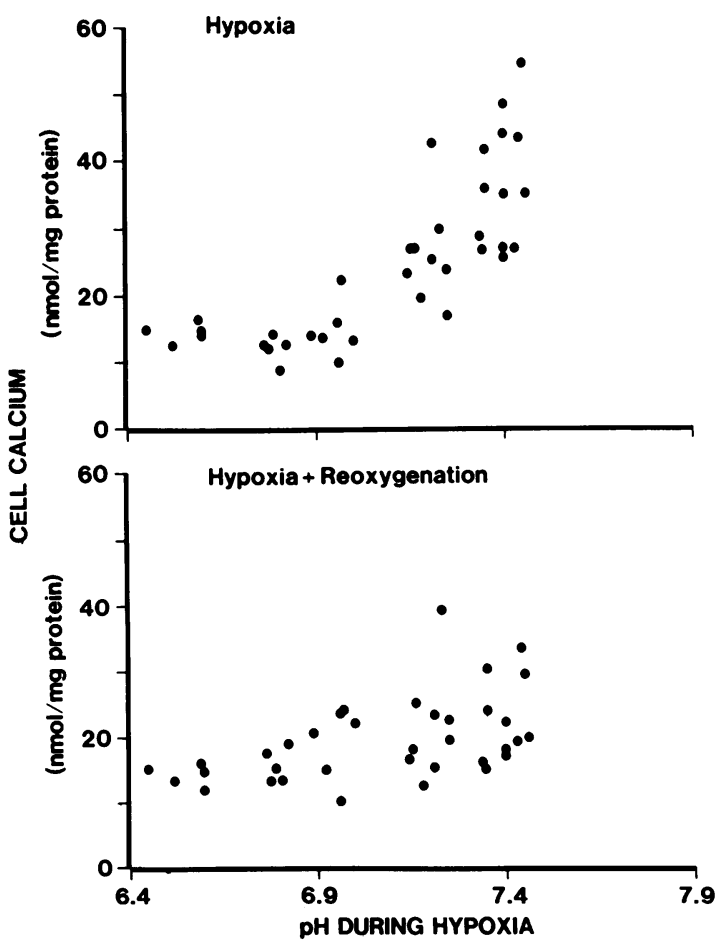

Figure 6. Cell $\mathrm{Ca}^{++}$as a function of suspension $\mathrm{pH}$ maintained during 30 min of hypoxia. (Upper panel) Values measured at the end of hypoxia. (Lower panel) Values after hypoxia plus $60 \mathrm{~min}$ of reoxygenation.

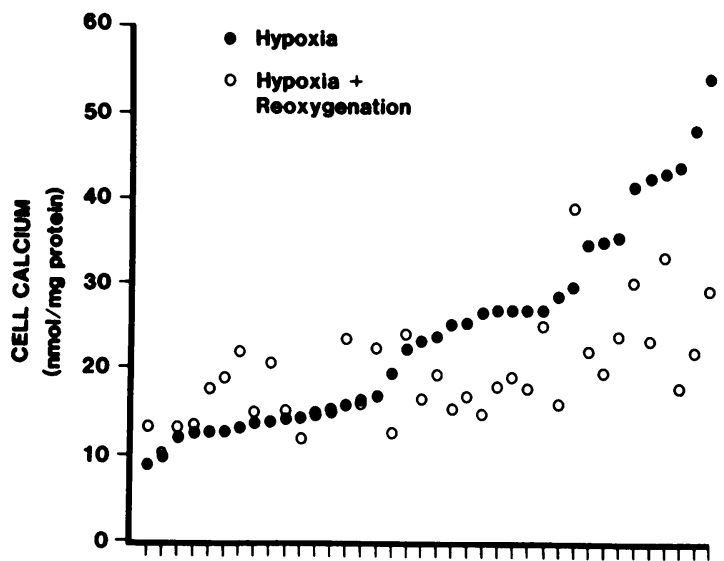

Figure 7. Cell $\mathrm{Ca}^{++}$levels measured at the end of $30 \mathrm{~min}$ of hypoxia (๑), compared to those measured after hypoxia plus $60 \mathrm{~min}$ of reoxygenation (o). Each vertical line on the abscissa indicates a single pair of experiments. Experiments are ordered according to $\mathrm{Ca}^{++}$levels at the end of hypoxia starting with the lowest values on the left.

ation, while, when $\mathrm{Ca}^{++}$was high during hypoxia, it fell with reoxygenation. Fig. 8 summarizes the relationship between percent protein recovery and cell $\mathrm{Ca}^{++}$measured at the end of hypoxia. A highly significant inverse correlation is present $(r$ $=-0.873, P<0.01$ ).

Figs. 9 and 10 summarize the behavior of cell adenine nucleotides in response to hypoxia as a function of the $\mathrm{pH}$ maintained during hypoxia. The data given are intracellular adenine nucleotide levels obtained by subtracting concentrations measured in the medium obtained after removal of tubule material by high-speed centrifugation from total suspension values and, thus, reflect contributions from the entire population of tubules. Tubules incubated at low pHs during hypoxia had significantly higher cell AMP levels than those maintained at high pHs ( $r$ $=-0.712, P<0.01$ for $\mathrm{pH}$ vs. AMP). Cell AMPs dropped toward levels seen in oxygenated control preparations during recovery, but cells maintained at low pHs during hypoxia still tended to have slightly higher AMP levels $(r=-0.328, P<0.05)$ than those which had been incubated at high pHs. The behavior of cell ATP was inverse to that of AMP. Cell ATP levels at the end of hypoxia tended to be slightly higher at low pHs $(r=-0.472$,

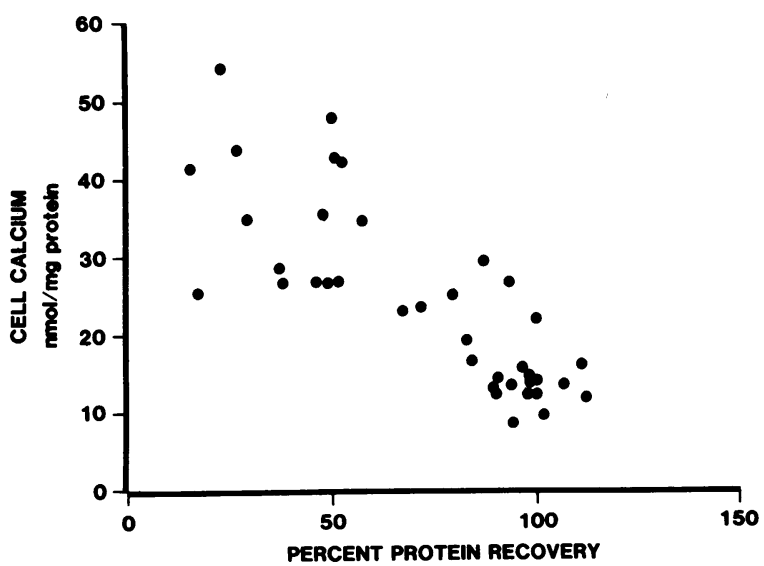

Figure 8 . Cell $\mathrm{Ca}^{++}$levels at the end of $30 \mathrm{~min}$ of hypoxia as a function of percent protein recovery at that point. 

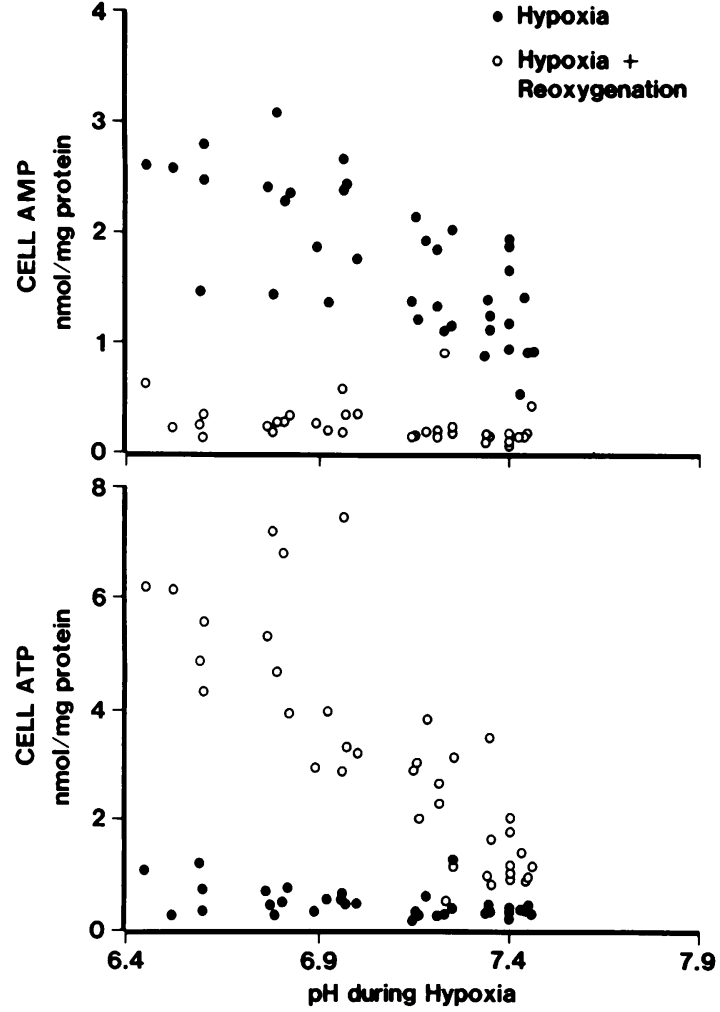

Figure 9. Cell AMP (upper panel) and ATP (lower panel) levels during hypoxia (•) and hypoxia plus reoxygenation (o) as a function of $\mathrm{pH}$ during hypoxia.

$P<0.01$ ), but the range of difference was small and some preparations made hypoxic at low pHs had ATP levels well below values seen at the higher pHs tested. Tubule cell ATP levels increased toward control values during recovery and the ATP levels reached correlated closely with the $\mathrm{pH}$ maintained during hypoxia $(r=-0.837, P<0.01)$. ADP levels showed relatively small changes under the conditions tested so that changes in total adenine nucleotides largely reflected the net effects of the alterations in AMP and ATP. These values for total adenine

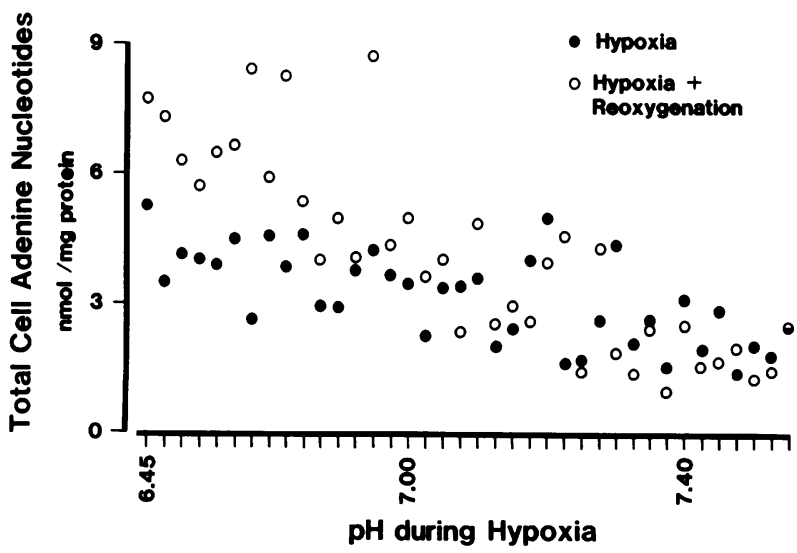

Figure 10. Total cell adenine nucleotide levels as a function of $\mathrm{pH}$ during hypoxia. Experiments are ordered from lowest to highest $\mathrm{pH}$. Each point on the abscissa indicates a single pair of experiments. (•) Samples studied at the end of hypoxia; (O) samples studied after hypoxia + reoxygenation. nucleotides are summarized in Fig. 10. The total adenine nucleotide pool was reduced relative to that in time controls during hypoxia but this reduction was less marked at low $\mathrm{pH}$. In tubules maintained during hypoxia at $\mathrm{pH}$ values below 7.0 the total adenine nucleotide pool always increased with recovery toward time control levels, usually by a substantial amount. With pH values above 7.0 during hypoxia, the response of the adenine nucleotide pool during recovery was much more variable. Further decreases relative to time control levels were observed in many preparations and, when increases were seen, they were generally small.

Morphologic observations. Tubule preparations consisted mainly of short lengths of well-preserved proximal tubules at the end of the preparation procedure. Trypan blue-positive cells were limited and were located mostly at the ends of tubule lengths. During incubation at $37^{\circ} \mathrm{C}$, good tubule lengths remained for the entire duration of study, however, more short lengths appeared with longer incubation times as did some Trypan blue-positive cells, mostly as individual cells free in the medium. 15 min of hypoxia resulted in moderately increased numbers of Trypan blue-positive cells within tubule lengths and as free material but most tubule cells did not sustain lethal cell injury by this criterion. With $30 \mathrm{~min}$ of hypoxia at pHs above 7.0 , there was a great increase in the amount of subcellular debris and of free cells, virtually all Trypan blue-positive. Of the remaining tubule lengths many had mostly Trypan blue-positive cells. Tubule preparations subjected to ischemia for 30 or 60 min or to hypoxia at pHs below 7.0 showed increases in the numbers of Trypan blue-positive cells mainly as free cells but most tubule lengths appeared to be as well preserved as those in time controls. In control and ischemic preparations, the tubule material pelleted by centrifugation through bromododecane appeared similar to that of the initial suspensions. In hypoxic preparations with severe injury, the bromododecane pellets contained a much higher proportion of intact lengths of tubules, fewer free cells, and less subcellular debris than present in the tubule suspensions prior to centrifugation.

\section{Discussion}

Tubule cell injury is a prominent component of ischemic acute renal failure, although its manifestations vary with the model studied $(3,4)$. As with ischemic cell injury in other tissues, a better understanding of the pathophysiology of ischemic acute renal failure at the tubule cell level could lead to more effective approaches to its prevention in the clinical setting. The study of ischemic cell injury in tubule cells from renal cortex is of additional relevance to understanding ischemic cell injury in general because of the feasibility of readily isolating intact renal tubules for study in vitro and the large amount of available data on the normal physiology and metabolism of such tubule preparations $(8,10,17,18,25,26)$.

This paper defines the suitability of isolated renal tubule preparations for studying ischemic cell injury and provides insight into several major processes in its pathogenesis. Prior studies have provided valuable data on the behavior of a number of metabolic and structural parameters of isolated hepatocytes and myocytes subject to hypoxic injury in vitro $(11-14)$. The present study is the first detailed report of this kind applicable to the kidney and provides a comprehensive analysis of the simultaneous behaviors of multiple critical injury-related metabolic parameters during an in vitro model fully characterized as to its 
acute time course, reversibility, and probable relationship to injury in vivo. The methods employed for tubule isolation in the present study included procedures similar to those described in recent reports detailing successful preparations of high quality proximal tubule-enriched suspensions of tubules from renal cortex $(17,27)$. No tissue preparation studied in vitro precisely reproduces the characteristics and stability of cells in vivo. Rather, some compromises must be accepted for the advantages of access and direct study of processes in a controlled experimental setting. Although incubated in simple salt solutions, the tubule preparation exhibits quite reproducible and stable function with regard to key cellular metabolic parameters for durations of incubation at $37^{\circ} \mathrm{C}$ in excess of $2 \mathrm{~h}$, a period in which the present study demonstrates that many of the acute events of ischemic renal tubular cell injury can be reproduced. The values for cellular electrolyte levels and adenine nucleotides compare closely with levels reported in vivo for renal cortex and to values for these parameters reported for prior isolated proximal tubule enriched suspension preparations $(18,19,26-30)$. No precise data are available for comparing the respiratory rates with rates in vivo, however, their stability, the marked stimulation of basal rates produced by uncouplers, and their similarity to respiratory rates previously reported in detail for other preparations of this type argue for a highly intact system $(18,31)$.

The parameters routinely measured on all tubule preparations cover major processes generally deemed important in the development of cell injury: the capacity for oxidative metabolism, the adenine nucleotide pool, and the ability of the cell to maintain its net monovalent cation and calcium homeostasis $(2,32)$.

30 min of hypoxia produced by changing the gas phase of the incubating flasks from $95 \% \mathrm{O}_{2} / 5 \% \mathrm{CO}_{2}$ to $95 \% \mathrm{~N}_{2} / 5 \% \mathrm{CO}_{2}$ resulted in striking changes in the tubule suspension during hypoxia and after hypoxia plus $60 \mathrm{~min}$ of recovery in oxygenated medium. Cell respiratory rates after reoxygenation were reduced to $<30 \%$ of time controls and, succinate, which did not stimulate uncoupled respiration in time controls, strikingly stimulated respiration. Stimulation of basal respiration by succinate has been used as an index of the presence of marked cell membrane injury and/or free mitochondria in studies of isolated hepatocytes in that neither respiration nor gluconeogenesis are stimulated by succinate in intact isolated hepatocytes or in isolated perfused liver but respiration is markedly stimulated by succinate in damaged, permeabilized hepatocytes (33-35). Renal tubules, in contrast, have a brush border membrane $\mathrm{Na}^{+}$-succinate cotransport system, which allows succinate to enter tubule cells (31), gain access to mitochondria, and stimulate metabolism and respiration in intact tubules and the isolated perfused kidney (27, $36,37)$. This likely accounts for the stimulation of basal rates by succinate in the experiment summarized in Table VI. To avoid this confounding factor in interpreting succinate stimulation as an index of injury, in the present study succinate was added during CCCLP-uncoupled respiration rather than during basal respiration. Succinate did not stimulate uncoupled respiration in control tubules but consistently did so in tubule preparations which, on the basis of other metabolic and morphologic parameters, had sustained lethal cell injury. The data summarized in Table VI show that succinate also produced a marked stimulation of basal respiration in the injured tubules, a result comparable to that reported for hepatocytes $(33,34)$. The extremely low basal and CCCLP-uncoupled respiratory rates of isolated mitochondria incubated in the tubule incubation me-
Table VII. Effects of Tubule Incubation Medium pH on Metabolic Parameters*

\begin{tabular}{|c|c|c|c|}
\hline & \multicolumn{2}{|c|}{ Tubules studied at medium pHs } & \multirow{2}{*}{$\begin{array}{l}\text { Correlation with } \\
\text { pH for all } \\
\text { tubules }(r)\end{array}$} \\
\hline & $>7.3$ & $<6.9$ & \\
\hline$n \ddagger$ & 15 & 11 & 38 \\
\hline \multicolumn{4}{|c|}{ Respiratory rates (natoms/min per mg protein) } \\
\hline BASAL & $51.1 \pm 2.0$ & $45.4 \pm 2.7$ & 0.283 \\
\hline CCCLP & $162.9 \pm 6.8$ & $141.9 \pm 6.1 \S$ & 0.287 \\
\hline \multicolumn{4}{|c|}{ Cell electrolyte levels ( $\mathrm{nmol} / \mathrm{mg}$ protein) } \\
\hline $\mathbf{K}^{+}$ & $313.8 \pm 8.5$ & $311.7 \pm 7.5$ & -0.100 \\
\hline $\mathrm{Ca}^{++}$ & $18.8 \pm 1.1$ & $13.7 \pm 0.6^{11}$ & $0.522 \pi$ \\
\hline
\end{tabular}

Protein recovery (\%)

$$
99.6 \pm 2.2 \quad 99.1 \pm 1.9 \quad-0.033
$$

Cell adenine nucleotides ( $\mathrm{nmol} / \mathrm{mg}$ protein)

$\begin{array}{llll}\text { ATP } & 6.96 \pm 0.26 & 7.08 \pm 0.18 & -0.012\end{array}$

\footnotetext{
* Values given are means \pm standard error.

$\ddagger n=$ number of tubule samples studied.

$\S P<0.05$.

" $P<0.001$ vs. $\mathrm{pH}>7.3$ tubules.

I $P<0.01$
}

dium before the addition of succinate suggest that free mitochondria and mitochondria in highly permeabilized cells do not contribute substantially to respiration measured during normal incubation conditions, but the addition of succinate, a substrate that they can metabolize, allows for the respiration of free mitochondria and mitochondria in damaged and highly permeabilized cells to be detected and utilized as an index of their presence and of the occurrence of the advanced cell injury which produced them. The stimulation produced by succinate in preparations with severe injury is only relative to the depressed rates in its absence. Maximal respiratory rates in the presence of succinate and CCCLP, irrespective of the order of their addition, are consistently, substantially less in the severely injured preparations than in the oxygenated control preparations reflecting irreversible damage to mitochondrial functional capacity.

The number of tubules sufficiently intact to have retained density characteristics allowing them to be separated from the suspension medium by the bromododecane centrifugation procedure was markedly diminished after $30 \mathrm{~min}$ of hypoxia as indicated by the reduced protein recovery in the sucrose-Ficoll layer. Cell $\mathrm{K}^{+}$in these recovered tubules was markedly reduced at the end of hypoxia. It increased substantially with reoxygenation but remained significantly reduced relative to time controls. Cell $\mathrm{Ca}^{++}$was significantly elevated at the end of hypoxia, then dropped with reoxygenation. Cell ATP estimated using total suspension measurements was strikingly reduced at the end of hypoxia as was the total adenine nucleotide pool because a moderate increase in cell AMP did not compensate for the decreases in ATP. Cell ATP recovered partially with reoxygenation but it, and, as a result, the total adenine nucleotide pool remained very low compared to time controls.

Morphologic observations indicated that $30 \mathrm{~min}$ of hypoxia resulted in the loss of most lengths of tubules and the conversion 
of most remaining tubule cells to being trypan blue-positive. Tubule material recovered after centrifugation through bromododecane was highly enriched in more intact-appearing tubules as compared to the total suspensions, however, lethally injured cells were also present.

Taken together, the metabolic and morphologic observations demonstrate that extensive lethal cell injury develops during 30 min of hypoxia. Measurements made on the total suspension and factored for total protein such as respiratory rates in the absence of succinate and estimated cell ATP levels probably reflect mainly the contribution of the remaining more intact tubules since isolated mitochondria do not effectively use glucose, lactate, alanine, or butyrate as respiratory substrates under the conditions used for tubule incubation (Table VI and reference 38) and free ATP in tubule suspensions is rapidly hydrolyzed (39). These more intact tubules are selectively separated by the bromododecane centrifugation procedure and thus may be quantified directly by measuring the amount of protein recovered in the sucrose-Ficoll layer.

15 min of hypoxia, despite producing major alterations in cell $\mathrm{K}^{+}$and ATP levels, did not produce widespread lethal renal tubular cell injury as indicated by good recoveries with oxygenation of respiratory function, cell $\mathrm{K}^{+}$, and adenine nucleotides, the maintenance of a relatively high protein recovery and the absence of substantial stimulation of respiration by succinate. Morphologic observations were consistent with this interpretation. It is of note, however, that evidence for some lethal cell injury with $15 \mathrm{~min}$ of hypoxia was present and protein recovery did fall significantly upon reoxygenation after $15 \mathrm{~min}$ of hypoxia relative to time controls. This evidence for lethal cell injury progressing during reoxygenation corresponds to the timing of the appearance of lethal cell injury in vivo, i.e., with reperfusion (3, 40), and is in contrast to the situation seen with $30 \mathrm{~min}$ of hypoxia, where, based on protein recoveries and morphology, most lethal cell injury occurred during hypoxia. Considering the 15and $30-\mathrm{min}$ data in combination, the results indicate the occurrence of a process accounting for simultaneous loss of large numbers of tubules with durations of hypoxia between 15 and $30 \mathrm{~min}$. This observation contrasts with substantial data from in vivo ischemia models in multiple species including the rabbit that indicate that renal proximal tubules uniformly survive 25$30 \mathrm{~min}$ of ischemia in vivo without substantial lethal cell injury during ischemia or reperfusion. Widespread lethal proximal tubule cell injury generally requires $60 \mathrm{~min}$ of ischemia (3, 40, 41).

In considering why tubules were apparently more susceptible to injury from hypoxia in vitro than from ischemia in vivo, cell density was a major factor that could contribute to the development of cell injury that distinguished the hypoxia model in vitro from ischemia in vivo. Tubules in the system studied in vitro were at relatively low density so that metabolic products generated by the tubules during oxygen deprivation and substrate availability would be less likely to influence the course of tubule cell injury than in the ischemic kidney in vivo. Therefore, in order to simulate more closely the conditions present during ischemia in vivo, tubules were gently pelleted by low-speed centrifugation at the beginning of oxygen deprivation and were kept as pellets until they were reoxygenated. Measurements of intracellular vs. extracellular water spaces in these pellets showed intracellular water to be $54 \%$ of total pellet water, a value somewhat less than the value of the kidney in vivo but far higher than the $1.6 \%$ estimated for tubules in suspension (data not shown).
The responses of tubules subjected to ischemia in vitro were strikingly different from those of tubules subjected to hypoxia, in that, based on all the quantitative metabolic parameters measured as well as on their morphologic appearance, ischemic tubules were highly protected from the development of oxygen deprivation-induced lethal cell injury. $30 \mathrm{~min}$ of ischemia produced as little or less injury than $15 \mathrm{~min}$ of hypoxia. Even more striking than this, although progressive injury between 30 and $60 \mathrm{~min}$ of ischemia was identifiable, it was moderate (e.g., protein recovery after $60 \mathrm{~min}$ of ischemia plus recovery exceeded $75 \%$ ) as compared to the explosive damage occurring between 15 and $30 \mathrm{~min}$ of hypoxia. Such protection occurred in spite of the manifestations of the full effects of hypoxia metabolically, e.g., ATP levels between 30 and $60 \mathrm{~min}$ of ischemia were no higher than those between 15 and $30 \mathrm{~min}$ of hypoxia in either whole suspensions or bromododecane separated tubule pellets. The protection afforded by pelleting the tubules during oxygen deprivation was shown not to relate to the absence of tubule agitation during that period. These data indicate that, when studied at densities closer to those present in vivo, the susceptibility of the isolated tubules to lethal cell injury induced by oxygen deprivation is very similar to that of ischemic tubules in vivo.

Measurements of $\mathrm{pH}$ within the tubule pellet during oxygen deprivation indicated that, in contrast to suspensions of hypoxic tubules that maintain their $\mathrm{pH}$ levels close to the 7.4 predicted from the bicarbonate- $\mathrm{CO}_{2}$ buffer system utilized, pelleted tubules were in an environment of $\mathrm{pH}$ approximating 7.0 for much of the period of oxygen deprivation, including the entire interval between 30 and $60 \mathrm{~min}$. This decrease in $\mathrm{pH}$ may have arisen from several factors. Even though proximal tubules are generally not considered to metabolize glucose extensively to lactate (2), $\mathrm{H}^{+}$production in the pelleted tubules could have resulted from hydrolysis of ATP. It is now recognized that ATP hydrolysis is likely to be the primary mechanism of cellular acidification during anoxia irrespective of the metabolic compensatory process employed to generate ATP anaerobically $(42,43)$. An additional factor which could have contributed to the acidification occurring in the pellet is $\mathrm{CO}_{2}$ generation resulting from any small amount of residual $\mathrm{O}_{2}$ remaining in solution after the gassing procedure. $\mathrm{CO}_{2}$ generation by tubules has been proposed to account for the slightly lower pH maintained by suspensions of tubules than by tubule medium alone when both are similarly equilibrated with $\mathrm{CO}_{2}$ (44). This phenomenon was seen in the present study in the oxygenated samples. Additionally, hypoxic tubule suspensions had slightly higher pHs than oxygenated suspensions, an observation consistent with a role for tubule $\mathrm{CO}_{2}$ generation in contributing to medium $\mathrm{pH}$.

Rapid falls in tissue pH to levels of 6.5-7.0 have been documented during in vivo ischemia in a number of tissues including the kidney $(45,46)$. Data available in the literature for a number of models of injury including myocardial hypoxia (47), mechanical (48) and hypoxic (32) injury to hepatocytes, hypoxic and toxic injury to Ehrlich ascites tumor cells $(49,50)$, and studies of renal cortical slices (51) have suggested that reduction of $\mathrm{pH}$ has protective effects against the development of cell injury. However, a broad consensus on this issue has not been reached and a recent report has proposed that the fall in $\mathrm{pH}$ during renal ischemia is a major mediator of cell injury in the kidney (46).

To more directly test the influence of $\mathrm{pH}$, the effects of altering medium pH in the range 6.41-7.45 were studied in both time control tubules and in tubules subjected to $30 \mathrm{~min}$ of hypoxia. Estimates of average intracellular $\mathrm{pH}$ values in time con- 
trol oxygenated tubules using the distribution of $\left[{ }^{14} \mathrm{C}\right] 5,5-\mathrm{di}-$ methyloxazolidine-2,4-dione (data not shown) gave results comparable to those previously reported for suspensions of renal tubules $(44,51,52)$ in that changes of the average intracellular $\mathrm{pH}$ paralleled changes of the medium $\mathrm{pH}$ and average cell $\mathrm{pHs}$ were slightly higher than medium pHs at medium pHs below 7.3. However, whole cell 5,5-dimethyloxazolidine-2,4-dione uptake measurements reflect a combination of mitochondrial and cystosolic $\mathrm{pHs}$ with mitochondrial $\mathrm{pH}$ being relatively alkaline to the cytosol (52-54), and the relationship between cytosolic and mitochondrial pHs is likely to change as mitochondria are deenergized during oxygen deprivation. Consequently, further studies of $\mathrm{pH}$ changes within each intracellular compartment will be required to precisely quantitate the behavior of intracellular $\mathrm{pH}$ in this system.

The results of the studies of the effects of medium $\mathrm{pH}$ manipulation on hypoxic injury indicated, on the basis of both the multiple metabolic criteria measured as well as the morphologic appearance of the tubules, that reducing medium $\mathrm{pH}$ in the range 7.45-6.41 during hypoxia exerts a striking protective effect against the development of oxygen deprivation-induced cell injury. Furthermore, the critical extracellular $\mathrm{pH}$ required for this protection to be virtually complete was $\sim 7.0$ - the steady-state value achieved in the pellet studies used to simulate ischemic injury. This suggests that the measured drop of $\mathrm{pH}$ in the ischemic pellets plays a major protective role and the falls in $\mathrm{pH}$ that occur during ischemia in vivo act in a similarly protective fashion. Tubules protected from hypoxia by reduced $\mathrm{pH}$ did show some signs of further injury during reoxygenation, i.e., mildly reduced protein recoveries and increased cell $\mathrm{Ca}^{++}$levels. These observations raise the intriguing possibility that the "correction" of tissue acidosis that occurs during postischemic reflow in vivo may at least transiently exacerbate cell injury, particularly in marginally reperfused areas, and thus contribute to the commonly observed phenomenon that most lethal cell injury appears gradually during reflow after ischemia rather than during ischemia (40).

In considering possible subcellular mechanisms by which reduced $\mathrm{pH}$ might be protective, it is of note that both cell $\mathrm{K}^{+}$ and ATP levels were nearly as low during hypoxia in tubules that were strongly protected as in those that were not. Although small, but significantly positive, inverse correlations between $\mathrm{pH}$ during hypoxia and cell content were observed for $\mathrm{K}^{+}$and ATP, a number of individual tubule preparations that were highly protected had values for these parameters lower than those seen in unprotected tubules. The improved preservation of cell AMP and total adenine nucleotide levels seen with low $\mathrm{pH}$ during hypoxia may simply reflect the fact that fewer tubules had totally lost structural integrity. These data suggest that the mechanism of action of low $\mathrm{pH}$ in protecting against oxygen deprivationinduced cell injury involves a process in the pathogenesis of injury more basic than altering cellular energy balance or monovalent cation homeostasis.

Strikingly lower cell $\mathrm{Ca}^{++}$levels were present in hypoxic tubules protected by low $\mathrm{pH}$ than in unprotected tubules. A similar difference in $\mathrm{Ca}^{++}$levels was seen in the experiments comparing hypoxic and ischemic tubules, suggesting that effects on intracellular $\mathrm{Ca}^{++}$metabolism may be involved in mediating the protection produced by low $\mathrm{pH}$. These observations must, however, be interpreted with caution because of the well-documented ability of mitochondria, even after the occurrence of lethal cell injury, to continue to actively sequester $\mathrm{Ca}^{++}(2)$. Every oxygen deprivation condition in the present series of studies in which an increase in tubule cell $\mathrm{Ca}^{++}$occurred was accompanied by disruption of renal tubule cells as indicated by diminished protein recovery with the bromododecane centrifugation procedure and morphologic appearance, whereas nonlethal insults were never accompanied by increases in cell $\mathrm{Ca}^{++}$. In this regard, the data are similar to those recently reported in a study of the development of nephrotoxic injury in vivo where no prolonged prelethal injury phase of net cell $\mathrm{Ca}^{++}$influx could be identified (19). Although $\mathrm{Ca}^{++}$determinations in the present study were done only on the pellet material recovered with bromododecane centrifugation, and this material was clearly enriched in the remaining viable tubules, some lethally injured material does appear in those pellets, and, given the high concentrations of $\mathrm{Ca}^{++}$ that can occur in mitochondria after lethal cell injury (19), such material may account for the elevations in $\mathrm{Ca}^{++}$measured. Further studies will be required to determine definitively whether the alterations of $\mathrm{Ca}^{++}$measured in this system are confined only to lethally injured cells or represent an intracellular accumulation of $\mathrm{Ca}^{++}$in cells not destined to become lethally cell injured.

Although a definitive pathogenetic role cannot yet be ascribed to $\mathrm{Ca}^{++}$based on the measurements in the severely injured tubules, additional evidence favoring such a role is available from the $\mathrm{pH}$ manipulation studies. Control oxygenated tubules incubated at low $\mathrm{pH}$ maintained significantly lower total intracellular $\mathrm{Ca}^{++}$levels than those incubated at normal $\mathrm{pH}$ levels. A similar effect of $\mathrm{pH}$ on renal tubule cell $\mathrm{Ca}^{++}$levels has been reported for isolated rat tubules (29). Although the mechanism for this reduction of cell $\mathrm{Ca}^{++}$and the subcellular loci of the effect remain to be elucidated, this observation suggests that low $\mathrm{pH}$ has the potential to alter cellular $\mathrm{Ca}^{++}$dynamics in normal and prelethally injured tubules and is consistent with observations that low pH reduces transmembrane $\mathrm{Ca}^{++}$flux in myocardial cells $(14,55)$ and that rises in cell $\mathrm{pH}$ appear to promote $\mathrm{Ca}^{++}$-mediated events during cellular differentiation and replication (43). It has been reported that the $k_{\mathrm{D}}$ for the binding of $\mathrm{Ca}^{++}$to calmodulin is $\sim 10$-fold higher $(0.25 \mu \mathrm{M})$ at $\mathrm{pH} 6.5$ than at pH $7.5(0.02 \mu \mathrm{M})(43,56)$. As noted by Busa and Nuccitelli (43), the ability of $\mathrm{pH}$ changes to alter both cell $\mathrm{Ca}^{++}$ homeostasis and $\mathrm{Ca}^{++}$calmodulin interactions allows changes in cell $\mathrm{pH}$ to play a potentially major role in modulating the numerous cellular processes regulated by $\mathrm{Ca}^{++}$and calmodulin. It is of importance, in this regard, that studies of activity of plasma membrane phospholipases $\mathrm{A}$ and $\mathrm{C}$ and mitochondrial phospholipases $\mathrm{A}$ have generally indicated that the $\mathrm{pH}$ optima for these enzymes are above 7.0 and rather sharp decreases in activity are observed below pH 7.0 (57-60). Inhibition of the activity of membrane phospholipases by reduced $\mathrm{pH}$ via effects on membrane $\mathrm{Ca}^{++}$and $\mathrm{Ca}^{++}$calmodulin as well as by direct effects on the enzymes themselves is a mechanism for the protective effects of reduced $\mathrm{pH}$ which should be explored.

In summary, a reproducible model of oxygen deprivationinduced injury to isolated proximal tubules has been developed and critical cellular metabolic features of the process have been analyzed and quantitated. Oxygen deprivation under hypoxic conditions is far more injurious than under simulated ischemic conditions. The fall in $\mathrm{pH}$ that occurs during ischemia appears to be sufficient to account for the reduced susceptibility to oxygen deprivation of ischemic tubules because $\mathrm{pH}$ changes of the same degree produce equivalent protection in hypoxic tubules. The protective effects of reduced $\mathrm{pH}$ may be mediated by alterations 
in cell $\mathrm{Ca}^{++}$handling, $\mathrm{Ca}^{++}$calmodulin interactions, and membrane phospholipase activity.

\section{Acknowledgments}

We thank Dr. Craig B. Langman of Michael Reese Hospital for helpful advice in perfecting the tubule isolation procedure and Dr. William $\mathbf{J}$. Butler of the University of Michigan School of Public Health for assistance with the statistical analysis. Technical support was provided during various phases of these studies by Mary Clark, Christine Holden, Deborah Hunt, Laura Pickford, Kim Tekkanat and Michael White. The expert secretarial assistance of Ms. Julie Armstead is gratefully acknowledged.

These studies were supported by National Institutes of Health grant AM 34275, American Heart Association Grant-in-Aid 83-1200, National Institutes of Health grant AM 30879-02-H. D. Humes Principal Investigator, Joel M. Weinberg, Co-Investigator, and by the Veterans Administration.

\section{References}

1. Stein, J. H., M. D. Lifschitz, and L. D. Barnes. 1978. Current concepts on the pathophysiology of acute renal failure. Am. J. Physiol. 243:F171-F186.

2. Humes, H. D., and J. M. Weinberg. 1983. Cellular energetics in acute renal failure. In Acute Renal Failure. B. M. Brenner and J. M. Lazarus, editors. W. B. Saunders, Philadelphia. 47-99.

3. Kreisberg, J. I., E. Matthys, and M. A. Venkatachalam. 1983. Morphologic factors in acute renal failure. In Acute Renal Failure. B. M. Brenner, J. M. Lazarus, editors. W. B. Saunders, Philadelphia. 21-46.

4. Solez, K. 1984. The pathology and pathogenesis of human acute tubuler necrosis. In Acute Renal Failure: Correlations Between Morphology and Function. K. Solez and A. Whelton, editors. Marcel Dekker, Inc., New York. 17-42.

5. Burke, T. J., R. Cronin, K. Duchin, L. Peterson, and R. Schrier. 1980. Ischemia and tubule obstruction during acute renal failure in dogs: mannitol in protection. Am. J. Physiol. 238:F305-F314.

6. Burke, T. J., P. E. Arnold, J. A. Gordon, R. E. Bulger, D. C. Dobayn, and R. W. Schrier. 1984. Protective effect of intrarenal calcium membrane blockers before or after renal ischemia. Functional, morphological, and mitochondrial studies. J. Clin. Invest. 74:1830-1841.

7. Siegel, N. J., W. B. Glaizer, I. H. Chaudry, K. M. Gaudio, B. Lytton, A. E. Baue, and M. Kashgarian. 1980. Enhanced recovery from acute renal failure by the postischemic infusion of adenine nucleotides and magnesium chloride in rats. Kidney Int. 17:338-349.

8. Burg, M. B., and J. Orloff. 1962. Oxygen consumption and active transport in separated renal tubules. Am. J. Physiol. 203:327-330.

9. Burg, M. B. 1982. Background and development of microperfusion technique. Kidney Int. 22:417-424.

10. Mandel, L. J. 1982. Use of noninvasive fluorometry and spectrophotometry to study epithelial metabolism and transport. Fed. Proc. 41:36-41.

11. Medzihradsky, F., and M. J. Marks. 1975. Measures of viability in isolated cells. Biochem. Med. 13:164-177.

12. Orrenius, S., T. Hjordis, J. Rajs, and M. Berggren. 1976. Isolated rat hepatocytes as an experimental tool in the study of cell injury. Effect of anoxia. Forensic Sci. 8:255-263.

13. Cheung, J. Y., I. G. Thompson, and J. V. Bonventre. 1982. Effects of extracellular calcium removal and anoxia on isolated rat myocytes. Am. J. Physiol. 243:C184-C190.

14. Altschuld, R. A., J. R. Hostetler, and G. P. Brierley. 1981. Response of isolated heart cells to hypoxia, reoxygenation and acidosis. Circ. Res. 49:307-316.

15. Trump, B. F., and R. E. Bulger. 1968. Studies of cellular injury in isolated flounder tubules. Lab. Invest. 18:721-730.
16. Trump, B. F., T. Sato, I. K. Berezesky, and K. V. Laiho. 1983. Cell calcium and anoxic cell death. Fed. Proc. 42:661.

17. Vinay, P., A. Gougoux, and G. Lemieux. 1981. Isolation of a pure suspension of rat proximal tubules. Am. J. Physiol. 241:F403-F411.

18. Harris, S. T., R. G. Balaban, L. Barrett, and L. J. Mandel. 1981. Mitochondrial respiratory capacity and $\mathrm{Na}^{+}$- and $\mathrm{K}^{+}$-dependent adenosine triphosphatase-mediated ion transport in the intact renal cell. $J$. Biol. Chem. 256:10319-10382.

19. Weinberg, J. M., P. G. Harding, and H. D. Humes. 1983. Alterations in renal cortex cation homeostasis during mercuric chloride and gentamicin nephrotoxicity. Exp. Mol. Pathol. 39:43-60.

20. Khym, J. X. 1975. An analytical system for rapid separation of tissue nucleotides at low pressures on conventional anion exchangers. Clin. Chem. 21:1245-1252.

21. Swain, J. L., R. L. Sabina, P. A. McHale, J. C. Greenfield, and E. W. Holmes. 1982. Prolonged myocardial nucleotide depletion after brief ischemia in the open chest dog. Am. J. Physiol. 242:H818-H826.

22. Lowry, O. H., N. J. Rosebrough, A. L. Farr, and R. J. Randall. 1951. Protein measurement with the Folin phenol reagent. J. Biol. Chem. 193:265-275.

23. Dixon, W. J. 1983. BMDP Statistical Software. University of California, Los Angeles. 359-387.

24. Edwards, A. L. 1968. Experimental Design in Psychological Research, 3rd edition. Holt, Rinehart and Winston, New York. 130-153.

25. Guder, W. G., O. H. Wieland, and B. Stukowski. 1972. Metabolism of isolated kidney tubules. Eur. J. Biochem. 31:69-79.

26. Rorive, G., R. Nielsen, and A. Kleinzeller. 1972. Effect of pH on the water and electrolyte content of renal cells. Biochim. Biophys. Acta. 266:376-396.

27. Balaban, R. S., S. P. Soltoff, J. M. Storey, and L. J. Mandel. 1980. Improved renal cortical tubule suspension: spectrophotometric study of $\mathrm{O}_{2}$ delivery. Am. J. Physiol. 238:F50-F59.

28. Burg, M. B., and J. Orloff. 1966. Effect of temperature and medium $\mathrm{K}^{+}$on $\mathrm{Na}^{+}$and $\mathrm{K}^{+}$fluxes in separated renal tubules. Am. J. Physiol. 211:1005-1010.

29. Studer, R. K., and A. B. Borle. 1979. Effect of $\mathrm{pH}$ on the calcium metabolism of isolated rat kidney cells. J. Membr. Biol. 48:3253/841.

30. Cunarro, J. A., S. E. Schultz, W. A. Johnson, and M. W. Weiner. 1982. Effects of ischemia on metabolite concentrations in dog renal cortex. Renal Physiol. 5:143-155.

31. Gullans, S. R., P. C. Brazy, V. W. Dennis, and L. Mandel. 1984. Interactions between gluconeogenesis and sodium transport in rabbit proximal tubule. Am. J. Physiol. 246:F859-F869.

32. Bonventre, J. V. 1984. Cellular response to ischemia. In Acute Renal Failure, Correlations Between Morphology and Function. K. Solez and A. Whelton, editors. Marcel Dekker, New York. 195-220.

33. Mapes, J. P., and R. A. Harris. 1975 . On the oxidation of succinate by parenchymal cells isolated from rat liver. FEBS (Fed. Eur. Biochem. Soc.) Lett. 51:80-83.

34. Baur, H., S. Kasperek, and E. Pfaff. 1975. Criteria of viability of isolated liver cells. Hoppe-Seyler's Z. Physiol. Chem. 356:827-838.

35. Hems, R., M. Stubbs, and H. A. Krebs. 1968. Restricted permeability of rat liver for glutamate and succinate. Biochem. J. 107:807815.

36. Wright, S. H., I. Kippen, and E. M. Wright. 1982. Stoichiometry of $\mathrm{Na}^{+}$-succinate cotransport in renal brush-border membranes. J. Biol. Chem. 257:1773-1778.

37. Nishiitsutsuji-Uwo, J. M., B. D. Ross, and H. A. Krebs. 1967. Metabolic activities of the isolated perfused rat kidney. Biochem. J. 103: 852-862.

38. Lehninger, A. L. 1982. Principles of Biochemistry. Worth, N. Y. 397-530.

39. Weinberg, J. M., M. Clark, and H. D. Humes. 1984. Effects of exogenous ATP on tubule cell ATP levels. Clin. Res. 32:459A.

40. Reimer, K. A., C. E. Ganote, and R. B. Jennings. 1972. Alterations in renal cortex following ischemic injury. Lab. Invest. 26:347-363.

41. Hanley, M. J. 1980. Isolated nephron segments in a rabbit model of ischemic acute renal failure. Am. J. Physiol. 239:F17-F23. 
42. Hochachka, P. W., and T. P. Mommsen. 1983. Protons and anaerobiosis. Science (Wash. DC). 219:1391-1397.

43. Busa, W. B., and R. Nuccitelli. 1984. Metabolic regulation via intracellular pH. Am. J. Physiol. 246:R409-R438.

44. Struyvenberg, A., R. B. Morrison, and A. S. Relman. 1968. Acidbase behavior of separated canine renal tubule cells. Am. J. Physiol. 214: 1155-1162.

45. Poole-Wilson, P. A. 1978. Measurement of myocardial intracellular pH in pathological states. J. Mol. Cell Cardiol. 10:511-526.

46. Bore, P. J., P. A. Sehr, L. Chan, K. R. Thulborn, B. D. Ross, and G. K. Radda. 1981. The importance of $\mathrm{pH}$ in renal preservation. Transplant. Proc. 13:707-708.

47. Bing, O., W. Brooks, and J. Messer. 1973. Heart muscle viability following hypoxia: protective effect of acidosis. Science (Wash. DC). 180: 1297-1298.

48. Bell, M., H. Lazarus, A. Herman, R. Egdahl, and A. Rutenberg. 1971. pH dependent changes in cell membrane stability. Proc. Soc. Exp. Bio. Med. 136:298-299.

49. Pentilla, A., and B. F. Trump. 1975. Studies on modification of the cellular response to injury. I. Protective effect of acidosis on p-chloromercuribenzene sulfonic acid-induced injury of Ehrlich ascites tumor cells. Lab. Invest. 32:690-695.

50. Pentilla, A., and B. F. Trump. 1974. Extracellular acidosis protects Ehrlich ascites tumor cells and rat renal cortex against anoxic injury. Science (Wash. DC). 185:277-278.

51. Kleinman, J. G., W. W. Brown, R. A. Ware, and J. H. Schwartz. 1980. Cell pH and acid transport in renal cortical tissue. Am. J. Physiol. 239:440-444.
52. Adler, S., E. Shoubridge, and G. K. Radda. 1984. Estimation of cellular $\mathbf{p H}$ gradients with ${ }^{31} \mathrm{P}-\mathrm{NMR}$ in intact rabbit renal tubular cells. Am. J. Physiol. C188-C196.

53. Hoek, J. B., D. G. Nicholls, and J. R. Williamson. 1980. Determination of the mitochondrial proton motive force in isolated hepatocytes. J. Biol. Chem. 225:1458-1464.

54. Strzelecki, T., J. A. Thomas, C. D. Koch, and K. F. LaNoue. 1984. The effect of hormones on proton compartmentation in hepatocytes. J. Biol. Chem. 259:4122-4129.

55. Vogel, S., and N. Sperelakis. 1977. Blockade of myocardial slow inward current at low pH. Am. J. Physiol. 233:99-103.

56. Tkachuk, V. A., and M. Y. Menshikov. 1981. Effect of pH on calcium binding properties of calmodulin and on its interaction with Ca-dependent cyclic nucleotide phosphodiesterase. Biokhimia. 46:965973.

57. Waite, J., G. L. Scherphof, F. M. G. Boshouwers, and L. L. M. Van Deenen. 1969. Differentiation of phospholipases A in mitochondria and lysosomes of rat liver. J. Lipid Res. 10:411-420.

58. Victoria, E. J., L. M. G. Van Golde, K. Y. Hostetler, G. L. Scherphof, and L. L. M. Van Deenen. 1971. Some studies of the metabolism of phospholipids in plasma membranes from rat liver. Biochim. Biophys. Acta. 239:443-457.

59. Goracci, G., G. Porcellati, and H. Woelk. 1978. Subcellular localization and distribution of phospholipases $\mathrm{A}$ in liver and brain tissue. Adv. Prostaglandin Thromboxane. Res. 3:55-67.

60. Schwertz, D. W., J. I. Kreisberg, and M. A. Venkatachalam. 1983. Characterization of rat kidney proximal tubule brush border membrane associated phosphatidylinositol phosphodiesterase. Arch. Biochem. Biophys. 224:555-567. 